\title{
ARQUITECTURAS FORMATIVAS DE LAS QUEBRADAS DE GUATACONDO Y TARAPACÁ A TRAVÉS DEL PROCESO ALDEANO (ca. 900 AC-1000 DC)
}

\section{FORMATIVE ARCHITECTURES OF THE GUATACONDO AND TARAPACÁ RAVINES THROUGH THE VILLAGE FORMATION PROCESS /ca. 900 BC- 1000 ADI}

\section{SimÓN URBina ArayA*, LEONOR AdÁn Alfaro** \& CONSTANZA PELLEGRINO HURTADO***}

A partir de la variabilidad e historicidad de tres tradiciones arquitectónicas del Período Formativo (ca. 900 AC-1000 DC), se plantea un proceso aldeano caracterizado por (1) modos de crecimiento competitivo de los grupos parentales, desde unidades residenciales simples hasta conglomerados/ complejos e intrincados barrios/sectores, y (2) una inversión decreciente y planificada en arquitectura comunal y pública, la cual pierde sus propiedades más cotidianas, aglutinantes, centrales e inclusivas (Pircas, Ramaditas y Guatacondo), para ser manejada como recurso de distinción asimétrica intrasitio (Caserones). Estos asentamientos documentan una conspicua y prolongada experimentación sociopolítica que interviene y reorganiza las relaciones de parentesco heredadas del Arcaico, ahora al servicio de identidades colectivas en tensión que se expresan y escenifican públicamente.

Palabras clave: arqueología de asentamiento, arquitectura pública, Período Formativo, desierto de Atacama

Based on the variability and historicism of three architectonic traditions of the Formative Period (ca. 900 BC-1000 AD), it is proposed village formation process characterized by 1) competitive modes of growth of the kinship groups from simple residential units to conglomerates/complexes and intricate neighborboods/ districts, and 2) an intentional and diminishing investment in public communal spaces, which lose their more everyday purposes of being central, inclusive and cohesive (Pircas, Ramaditas, Guatacondo) in favor of the more asymmetrical use of this resource within the site (Caserones). These settlements document a conspicuous and lengthy sociopolitical experiment that intervenes in and reorganizes kinship relations inherited from the Archaic period to serve collective identities in tension that are expressed and played out in the public sphere.

Key words: settlement archaeology, public architecture, Formative period, Atacama Desert

\section{INTRODUCCIÓN}

La arquitectura aglutinada ubicada en la región geográfica de Tarapacá (Niemeyer 1989) ha sido materia de importantes contribuciones, las que, manteniendo su vigencia, han motivado nuevos estudios sobre sus primeras y notables expresiones en los inicios del Período Formativo o Intermedio Temprano. Desde las investigaciones de Grete Mostny en la aldea de Guatacondo (1970 y de 1980; véase también De Bruyne 1963) y de Núñez en Caserones (1966), así como el primer estudio comparativo entre ambos sectores realizado por Meighan y True (1980), un tema aún vigente es la forma en que se ha estudiado la arquitectura formativa en el proceso aldeano. Tradicionalmente utilizados para enfatizar los cambios en el modo de vida cazador-recolector y la emergencia de sociedades más complejas, el estudio arqueológico de estos asentamientos ha intentado comprender las razones y las determinantes por las cuales dichas poblaciones optaron por los beneficios de la vida aldeana, a veces aparentes, en relación con los estímulos de las economías productoras de alimentos (Núñez 1982, 2006; Núñez \& Santoro 2011).

Ahora bien, los cambios en el patrón de asentamiento durante este período (900 AC-1000 DC) pueden ser percibidos también por el establecimiento de cementerios colectivos fuera de los poblados (Ayala

* Simón Urbina Araya, Facultad de Filosofía y Humanidades, Instituto de Ciencias Sociales, Universidad Austral de Chile, Casilla 567, Valdivia, Chile, email: simon.urbina@uach.cl

* Leonor Adán Alfaro, Dirección Museológica, Universidad Austral de Chile, Casilla 586, Valdivia, Chile, email: ladan@uach.cl

*** Constanza Pellegrino Hurtado, Av. Kennedy 9590, Depto. 202, email: cony_france@yahoo.es 
2001), infraestructura productiva, caminos y paraderos, señalética monumental e instalaciones ceremoniales asociadas (Briones et al. 2005). Por esta razón, es necesario preguntarse si estas instalaciones responden únicamente al impacto económico de la agricultura y la vida aldeana y cómo se relacionan con las aldeas de las quebradas de Guatacondo y Tarapacá. Hasta el momento disponemos de respuestas solo parciales sobre la diversidad de asentamientos con arquitectura entre el 900 AC y 1000 DC, pues nuestra disciplina ha asumido una definición rígida del Formativo como aquel tiempo propio de las formaciones aldeanas, aislando el estudio de un conjunto amplio de tipos de sitios sincrónicos. A pesar de la escasa relevancia que, hasta hace poco, tuvo en los círculos arqueológicos americanos discutir aquella noción del Período Formativo como análogo al del Neolítico europeo (Blanton et al. 1996), Lumbreras (2006: 12-13) ha indicado que la evidencia histórica pone el concepto de "Formativo" en cuestión, puesto que no posee valor cronológico, histórico, evolutivo, ni es indicador de período o de época.

Retomando lo anterior, en el presente artículo intentamos relativizar aquel criterio evolucionista arbitrario, según el cual el cambio del modo de producción de las sociedades andinas arcaicas es el fundamento de su progreso y bienestar material. Según nuestros resultados, las distintas modalidades de vida aldeana en ámbitos desérticos no señalan necesariamente el fin de la arquitectura temprana o Arcaica durante el Período Formativo (Adán \& Urbina 2007). El tránsito hacia asentamientos altamente aglutinados, localizados solo en ciertos puntos de la región de estudio, es un aspecto que participa e incide desigualmente en el patrón de asentamiento tarapaqueño regional; por ello, constituye un ámbito muy excepcional de la ocupación humana en estas zonas desérticas andinas. Complementariamente, el análisis a continuación permite distinguir ejes donde apreciamos significativos cambios e innovaciones en la arquitectura y patrones constructivos: el ámbito doméstico, los edificios públicos y la traza aldeana. En estos términos, abordaremos el estudio descriptivo y comparativo de la arquitectura aglutinada de las quebradas de Guatacondo y Tarapacá.

\section{EL PERÍODO FORMATIVO EN TARAPACÁ Y SU ARQUITECTURA}

En el presente artículo retomaremos el estudio de las aldeas de Tarapacá (Núñez, P. 1983; Núñez, L. 1989). Nuestro objetivo es entender mejor la complejidad social de sus comunidades (sensu Castro et al. 1993) para discutir y problematizar algunos aspectos significativos de la historia cultural de este crucial período (Formativo) en los Andes Centro Sur (Adán \& Urbina 2007: 22). Se tratará individualmente el comportamiento cualitativo y cuantitativo de la arquitectura bajo parámetros que luego son comparados y discutidos a nivel intersitio. Con este propósito se utilizarán algunos indicadores constructivos que facilitan este análisis, los cuales hemos detallado en trabajos previos (Urbina \& Adán 2006; Adán \& Urbina 2007, 2008, 2010; Urbina et al. 2011, 2012; Urbina 2010). Los cuatro asentamientos ubicados en las quebradas de Guatacondo (aldea de Ramaditas y aldea de Guatacondo) y Tarapacá (aldea de Caserones y Pircas) documentan una significativa variabilidad y cambio de los sistemas aldeanos tarapaqueños.

El estudio de la arquitectura del Período Formativo que hemos desarrollado en Atacama (Adán \& Urbina 2007) y Tarapacá (Adán et al. 2007) recoge las propuestas metodológicas formuladas por Castro y colaboradores (1993), Adán (1999) y Romero y Briones (1999). De esta forma, discriminamos un conjunto de variables descriptivas principales que permiten una caracterización sincrónica y morfofuncional de los asentamientos (p. ej., superficie de los sitios, tamaño y forma de las plantas, tipos de paramentos), conscientes de que la planta final de los sitios es resultado de una historia ocupacional dinámica, difícil de definir únicamente con estudios superficiales.

Una de las ventajas del análisis morfofuncional desarrollado es que provee de indicadores comparables sobre la organización social de los habitantes de cada sitio. Las convergencias y las divergencias relativas a la tecnología y las opciones de diseño que existen usualmente entre un conjunto de asentamientos coetáneos indican grados de autonomía, áreas de integración directa o a distancia, corresidencia, conflicto o límites espaciales, étnicos y políticos que los distinguen o acercan a otras regiones. Por esta razón, los tipos de asentamiento formulados al nivel de la comunidad han sido utilizados operacionalmente para analizar y reunir modelos estructurales de conductas culturales y sociales en comunidades particulares y proveer una base comparativa intercomunitaria dirigida hacia la determinación de relaciones históricas (Trigger 1967: 151; Chang 1968: 5).

Previamente hemos aplicado los índices de Densidad Ocupacional o Edilicia (cfr. Uribe et al. 2002), Inversión de Trabajo (Urbina \& Adán 2006; Urbina 2010) y Factor de Ocupación de Suelo (FOS, sensu Raffino 1990; Urbina et al. 2011, Tabla 2: 70), intentado comparar en forma sistemática datos originalmente relevados para el estudio descriptivo intrasitio (sensu Cornejo 2007: 9-12). El primer índice permite resumir el grado de dispersión o aglutinamiento de las estructuras, si esta es proyectada 
sobre un terreno ideal de 100 x $100 \mathrm{~m}$, y se obtiene dividiendo el número total de las estructuras por la superficie en hectáreas (ha) del asentamiento (Urbina 2007: nota 7, 34). El segundo índice refiere a la superficie construida (SC) que totalizan las áreas internas de las estructuras, el cual se utiliza para entender el grado de inversión y diferenciación arquitectónica entre sitios. Sea esta inversión dirigida a la reducción, la ampliación o la habilitación de los espacios intramuro, debe estimarse que opera y representa un indicador de "energía humana" involucrada en la producción y/o modificación de los edificios durante su vida útil (McGuire \& Schiffer 1983). El tercer índice señala la proporción ocupada por la superficie construida (SC) de todas las estructuras dentro de la superficie total del asentamiento (ST), la cual incluye vías de circulación, espacios no edificados y entre recintos (Urbina et al. 2011: 67, nota 9). Los tres indicadores aportan sustancialmente a evaluar en forma sincrónica y diacrónica los patrones y las recurrencias espaciales en sitios de un mismo período y región, y especialmente a identificar tendencias sectoriales intrasitio y criterios normados de crecimiento, distancia y proximidad entre las unidades domésticas, o entre estas y espacios públicos.

Necesariamente, a la par de este razonamiento cuantitativo, se debe reflexionar sobre los procesos sociales relacionados con la organización espacial y las tecnologías constructivas identificadas, especialmente sus continuidades, variaciones y rupturas (Urbina \& Adán 2007: 19-20). Esto implica evaluar los modos de producción, uso y mantenimiento de la arquitectura en distintos ambientes o estaciones, ya sean espacios domésticos, productivos, públicos o funerarios (Willey 1968; McGuire \& Schiffer 1983). No menos importante es atender a las restricciones, las capacidades y los privilegios que las clases funcionales (p. ej., viviendas, talleres, plazas, monumentos funerarios, templos u otros) y sus atributos constructivos imponen u otorgan a sus usuarios dentro de un asentamiento o en una red de ellos (Moore 1996). En fin, se deben considerar estas cualidades físicas y simbólicas de los edificios como elementos transmisores de información que identifican, al modo de "diacríticos culturales", a sus ocupantes en la vida cotidiana y que, en la práctica, aluden a cierto "poder de acción" o "capitales" (sensu Nielsen 1995, en referencia a Bourdieu 1977) que ciertos grupos o individuos poseen o aspiran poseer dentro del ámbito social mayor al de su propia familia o red de parentesco más cercana.

Debido a que nuestra investigación contempla un amplio espacio geográfico del norte de Chile -delimitado por las cuencas de los ríos Camiña y Loa, así como por la costa Pacífico y el altiplano de la región-, hemos impuesto una lectura de la historia local de los asentamientos y sus unidades domésticas de acuerdo a la propuesta elaborada por Trigger $(1967,1968)$. Esta mirada, que se define como de abajo-arriba en términos de la estructura del patrón de asentamiento (Aldunate et al. 1986), considera también la ubicuidad, la envergadura y la posición de los espacios públicos, ceremoniales y productivos dentro de regiones formativas más amplias en los Andes Centro Sur (Raffino 1977).

En el presente trabajo planteamos un enfoque denominado "historia arquitectónica", el cual nos permite abordar el estudio de diversos espacios habitados por las sociedades tarapaqueñas (Adán \& Urbina 2008). Este se centra en el proceso diacrónico en el cual la arquitectura toma parte como un elemento singular (inmueble) y, a la vez, contenedor de otras manifestaciones de la cultura material y de la interacción humana en sí. Junto a las modalidades constructivas tempranas (Urbina et al. 2011, 2012), la "arquitectura formativa de tierras altas o temprana" y la denominada "arquitectura formativa en barro del ámbito de oasis" constituyen las dos tradiciones arquitectónicas definidas para entender la historia cultural del Período Formativo en el norte de Chile (Adán \& Urbina 2007: 24-26), permitiéndonos dar cuenta justamente de aspectos conservadores, innovadores y promocionales de la arquitectura aldeana y sus relaciones históricas.

Con todo, las construcciones de este lapso temporal (900 AC-1000 DC) más que reflejar puramente la adaptación a un clima -costa, valle o altiplano-, expresan también las habilidades y la tecnología de sus habitantes, las preferencias estéticas arraigadas, las innovaciones importadas (exóticas) u otras innovaciones promocionadas desde ámbitos rituales (Parker Pearson 1982; Urton 1988; Hodder 1990), las cuales lentamente pudieron ser integradas como rasgos conspicuos de las estructuras domésticas o públicas (Adán \& Urbina 2007). En estos términos, es esperable que las poblaciones costeras y de valles interiores de Tarapacá promovieran desde el Período Arcaico Tardío (2000-1000 AC) distintas modificaciones arquitectónicas en sus espacios habitacionales, producto de factores socioculturales, factores secundarios físico-climáticos u otras modificaciones (cfr. Rapoport 1969: 46-47).

\section{CUATRO CASOS DE ARQUITECTURA TARAPAQUENA AGLUTINADA}

Nuestra metodología busca avanzar en el tratamiento de los inmuebles Formativos en los valles interiores de Guatacondo y Tarapacá, implementando un análisis 
sistemático de los datos relevados, ${ }^{1}$ homólogo al efectuado previamente en siete asentamientos de la costa tarapaqueña (Urbina et al. 2011). Con este propósito, se efectuó el registro superficial de cuatro sitios ubicados en dos cuencas aledañas a la Pampa del Tamarugal (fig. 1): en Guatacondo, aldea de Ramaditas (Rivera et al. 1995-1996; Graffam et al. 1996; Martindale 2005) y aldea de Guatacondo (De Bruyne 1963; Mostny 1970; Meighan 1980), y en Tarapacá, aldea de Caserones (Núñez, L. 1966, 1982, 2006; True 1980; Adán et al. 2007) y el campamento de Pircas (Núñez, L. 1984).

En la escala de nuestro análisis hemos considerado el procedimiento utilizado por Trigger (1967: 151, 1968: 55, 74), efectuando un análisis del patrón de asentamiento en tres niveles: a) los edificios individuales o estructuras como indicadores de la organización familiar, especialización productiva y variación de la organización social; b) la manera en que dichas estructuras se ordenan en un asentamiento o comunidad, información relacionada con la organización de los linajes y la adaptación de la comunidad a su entorno natural y cultural, y c) la distribución de los asentamientos o comunidades en el paisaje, indicadores generales de la clase de organización sociopolítica, intercambio y conflicto interfamiliar o intercomunitario.

Con fines comparativos, junto con documentar las tradiciones constructivas presentes, se enfatizó la interacción entre labor y costo social de construcción, uso, mantenimiento de las estructuras, a través de variables e indicadores relacionados: envergadura o superficie total (ST) superficie construida intramuros (SC), densidad edilicia $\left(\mathrm{N}^{\mathrm{o}}\right.$ est. / ha [ST]) y porcentaje o factor de suelo ocupado (SC*100/ST) por distintos tipos de recintos (Tabla 1). La energía invertida en cada sitio ha sido estimada considerando la superficie construida intramuros (SC) en $\mathrm{m}^{2}$, ponderando el trabajo que demandó el emplazamiento de las estructuras, los tipos de paramentos utilizados, el aparejo, el trabajo de los materiales y el acabado de superficie interior y fachadas (Tabla 2). ${ }^{2}$

Tabla 1. Índices arquitectónicos por sitio.

Table 1. Architectonic indexes, by site.

\begin{tabular}{|c|c|c|c|c|c|c|c|}
\hline Sitio & $\begin{array}{c}\mathrm{N}^{\circ} \\
\text { estructuras }\end{array}$ & $\begin{array}{c}\text { Superficie } \\
\text { construida } \\
\left(\mathrm{m}^{2}\right)\end{array}$ & $\begin{array}{l}\text { Superficie } \\
\text { acumulada } \\
\text { plazas }\left(\mathrm{m}^{2}\right)\end{array}$ & $\begin{array}{l}\text { Superficie } \\
\text { (ha) }\end{array}$ & $\begin{array}{l}\text { Densidad } \\
\text { edilicia }\end{array}$ & $\begin{array}{c}\text { Factor de } \\
\text { ocupación } \\
\text { de suelo } \\
\text { (\%) }\end{array}$ & $\begin{array}{c}\text { Factor de } \\
\text { ocupación de } \\
\text { suelo espacios } \\
\text { públicos (\%) }\end{array}$ \\
\hline Ramaditas & 83 & 2369,5 & 1148,0 & 9,23 & 9,00 & 2,56 & 48,45 \\
\hline Guatacondo & 177 & 4215,1 & 1838,0 & 0,78 & 227,00 & 53,91 & 43,61 \\
\hline Pircas & 562 & 6594,1 & 2058,0 & 89,89 & 6,25 & 0,73 & 31,21 \\
\hline Caserones & 646 & 15996,2 & 3415,0 & 3,75 & 172,27 & 42,65 & 21,35 \\
\hline
\end{tabular}

Tabla 2. Características de los paramentos por sitio. Table 2. Wall features, by site.

\begin{tabular}{|c|c|c|c|c|c|c|c|c|c|c|c|c|c|c|c|c|c|c|}
\hline \multirow{2}{*}{ Sitio } & & \multicolumn{6}{|c|}{ Hilada } & \multicolumn{6}{|c|}{ Aparejo } & \multicolumn{3}{|c|}{ Materiales } & \multicolumn{2}{|c|}{ Ancho muro } \\
\hline & & Simple & Doble & $\begin{array}{l}\text { Doble/ } \\
\text { relleno }\end{array}$ & $\begin{array}{l}\text { Doble/ } \\
\text { simple }\end{array}$ & $\mathrm{N} / \mathrm{O}$ & Total & Rústico & Revestido & $\begin{array}{c}\text { Rústico/ } \\
\text { sedimentario }\end{array}$ & Sedimentario & $\mathrm{N} / \mathrm{O}$ & Total & Piedra & Mortero & Otros & $\begin{array}{l}\text { Mín. } \\
\text { (m) }\end{array}$ & $\begin{array}{l}\text { Máx. } \\
\text { (m) }\end{array}$ \\
\hline \multirow{2}{*}{ Ramaditas } & $\mathrm{n}$ & 14 & 34 & 6 & 4 & 25 & 83 & 1 & & 7 & 2 & 73 & 83 & \multirow{2}{*}{$\mathrm{x}$} & \multirow{2}{*}{$\mathrm{x}$} & \multirow{2}{*}{$\mathrm{x}$} & \multirow{2}{*}{0,12} & \multirow{2}{*}{0,6} \\
\hline & $\%$ & 16,86 & 40,96 & 7,22 & 4,81 & 30,12 & 100,00 & 1,20 & & 8,43 & 2,40 & 87,95 & 100,00 & & & & & \\
\hline \multirow{2}{*}{ Guatacondo } & $\mathrm{n}$ & 41 & 12 & & 7 & 117 & 177 & & & & 2 & 175 & 177 & \multirow{2}{*}{$\mathrm{x}$} & \multirow{2}{*}{$\mathrm{x}$} & \multirow{2}{*}{$\mathrm{x}$} & \multirow{2}{*}{0,12} & \multirow{2}{*}{1,1} \\
\hline & $\%$ & 23,16 & 6,77 & & 3,95 & 66,10 & 100,00 & & & & 1,12 & 98,87 & 100,00 & & & & & \\
\hline \multirow{2}{*}{ Pircas } & $\mathrm{n}$ & 233 & 59 & 27 & 4 & 239 & 562 & 128 & & & & 434 & 562 & \multirow{2}{*}{$\mathrm{x}$} & \multirow{2}{*}{$\mathrm{x}$} & \multirow{2}{*}{$\mathrm{x}$} & \multirow{2}{*}{0,1} & \multirow{2}{*}{1,38} \\
\hline & $\%$ & 41,45 & 10,49 & 4,80 & 0,71 & 42,52 & 100,00 & 22,77 & & & & 77,22 & 100,00 & & & & & \\
\hline \multirow{2}{*}{ Caserones } & $\mathrm{n}$ & 245 & 30 & 226 & & 135 & 636 & 124 & 94 & & 159 & 259 & 636 & & \multirow{2}{*}{$\mathrm{x}$} & \multirow{2}{*}{$\mathrm{x}$} & \multirow{2}{*}{0,07} & \multirow{2}{*}{1,57} \\
\hline & $\%$ & 38,50 & 4,70 & 35,50 & & 21,20 & 100,00 & 19,50 & 14,70 & & 25,00 & 40,70 & 100,00 & & & & & \\
\hline
\end{tabular}




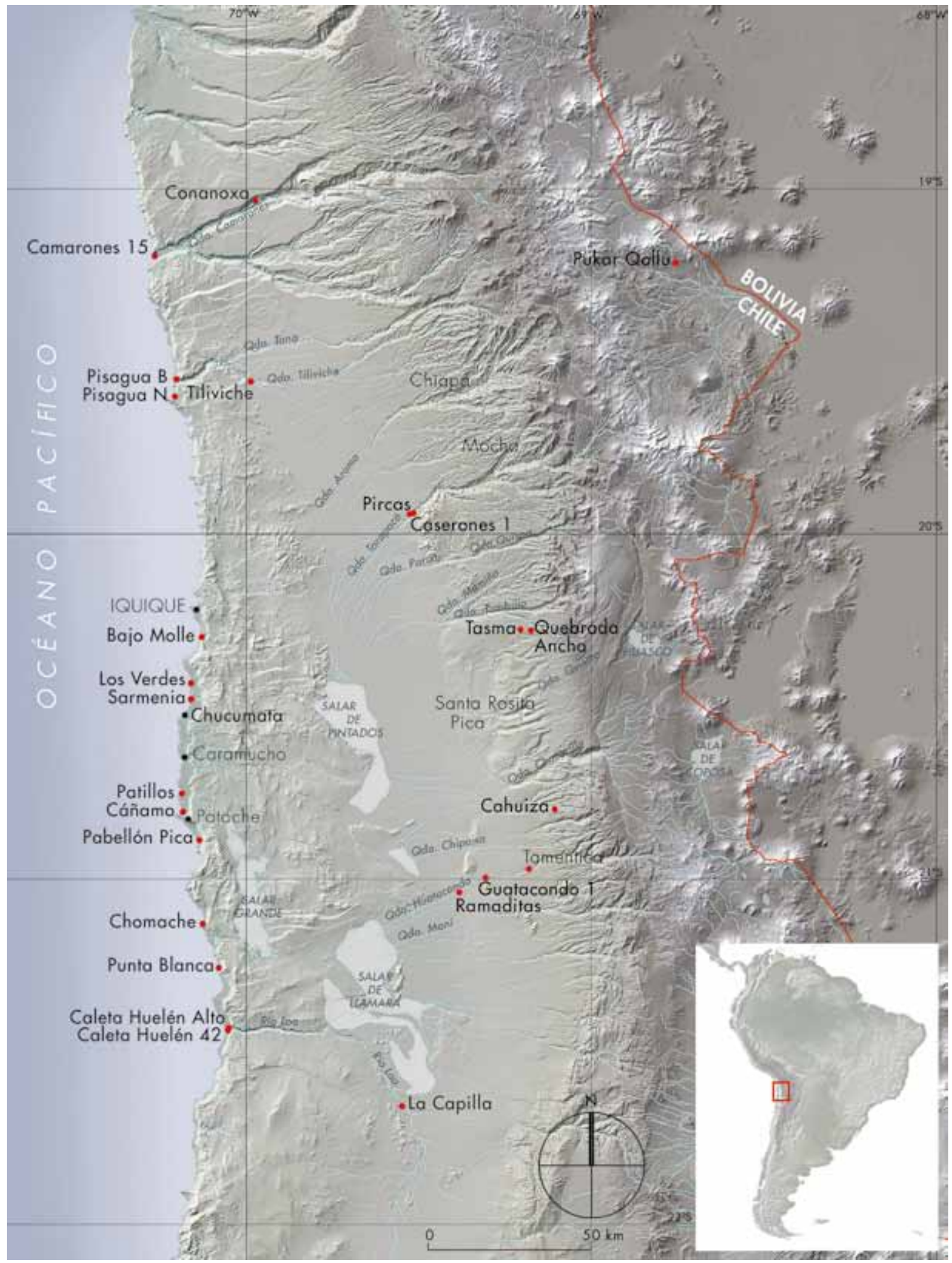

Figura 1. Región de Tarapacá con los principales sitios Formativos mencionados en el texto.

Figure 1. Tarapaca Region showing the main Formative sites mentioned in the text. 


\section{Quebrada de Guatacondo}

\section{Ramaditas}

El sitio Ramaditas se ubica a 1115 msnm y $150 \mathrm{~m}$ al norte de la quebrada de Guatacondo. Ha sido estudiado intensivamente por Rivera y su equipo desde el año 1990 (Rivera et al. 1995-1996; Graffam et al. 1996; Rivera 2005), los cuales la describen como una aldea de tres hectáreas compuesta por tres conjuntos arquitectónicos -un montículo, estructuras domésticas individuales y una importante área dedicada a campos de cultivo-, asociados con el acceso a cursos de agua y aprovechamiento de obras hidráulicas, como queda representado en las inmediaciones del yacimiento (Rivera et al. 19951996: 220-222). El sitio (UTM 7.675.673 N; $462.024 \mathrm{E}$, figs. $2 \mathrm{a}$ y b) se ubica en las proximidades de un extenso sistema agrohidráulico al norte del curso inferior de la quebrada de Guatacondo, ocho kilómetros al suroeste de las minas de cobre del cerro Challacollo (Graffam et al. 1996). Se encuentra a menos de una jornada de camino a pie de otros asentamientos formativos de la quebrada, como G-VII y G-I (12 km) (Mostny 1980), por lo cual documenta una secuencia ocupacional con grados de sincronía aún poco establecidos por las dataciones absolutas publicadas (Tartaglia 1980; Rivera 2005).

Según nuestros registros, el asentamiento se compone de 83 estructuras organizadas en tres grandes conglomerados, asimilables a los conjuntos antes descritos por Rivera y colaboradores (1995-1996) y Martindale (2005), un montículo con estructuras, conglomerados menores y estructuras dispersas. Todas ellas delimitan un perímetro cuya superficie alcanza las 9,23 ha con una bajísima densidad edilicia de nueve estructuras por hectárea de terreno. La superficie construida intramuros es de $2369,5 \mathrm{~m}^{2}$, de tal manera que el Factor de Ocupación de Suelo alcanza un 2,6\% de superficie destinada a construcciones (Tabla 1).

Nuestro registro identifica en términos formales que las estructuras de muros curvos son efectivamente predominantes, con un $62,6 \%$ de representatividad, y dentro de estas dominan las plantas ovales con una frecuencia cercana al 29\%, seguidas por aquellas de forma circular con el 16,86\% (Tabla 3). Las plantas irregulares poseen un $33,7 \%$ de presencia, usualmente configurando espacios entre recintos, vestíbulos o vías de circulación cuyas formas pueden ser compuestas o poligonales. Destaca la relativa ausencia de plantas con ángulos rectos (rectangulares, cuadrangulares), las cuales solo alcanzan una mínima representación estadística, bajo el $4 \%$.

Los tamaños registrados oscilan entre $1,5 \mathrm{~m}^{2} \mathrm{y}$ $489,5 \mathrm{~m}^{2}$, ubicándose un $60,24 \%$ en el segundo y tercer rango de tamaño (5-20,1 $\left.\mathrm{m}^{2}\right)$, mientras un $15,7 \%$ en el primer rango $\left(0-5,1 \mathrm{~m}^{2}\right)$. Es significativa la ocurrencia de estructuras (8,4\%) en el rango de plantas con superficies mayores a $60,1 \mathrm{~m}^{2}$ (Tabla 4). De acuerdo a esta información, Ramaditas constituye un asentamiento internamente disperso, más bien segmentado, el cual demuestra un amplio espectro funcional coherente con lo planteado en investigaciones previas. Posee un carácter eminentemente doméstico de patrón oval y circular -donde debieron ocurrir funciones de bodega, dormitorio, cocina y patios como áreas de actividad diaria- y en torno a espacios mayores de congregación de las unidades domésticas, como plazas o patios comunales (E.1, 22, 54). Los espacios domésticos, considerando su ubicación en el segundo y tercer rango de tamaño, debieran ascender a 49 o 50 unidades dentro del asentamiento. También debieron existir espacios de almacenaje y basurales, quizás amparados junto a los muros, al interior y exterior de los conglomerados principales.

Los paramentos entregan relevante información sobre elementos constructivos de Ramaditas (Tabla 2), los cuales se agregan a los previamente descritos por Martindale (2005: 146-147). En primer lugar, del total de paramentos registrados $(\mathrm{N}=83)$ se detectaron mayoritariamente muros dobles, dobles con relleno o que presentan en alguna sección del muro estas características $(52,9 \%)$ y una baja frecuencia de muros simples, con un 16,86\% de representación. La piedra, los adobes irregulares de barro y el mortero de barro utilizado con mayor o menor cantidad de inclusiones han sido los elementos principales de la arquitectura de Ramaditas. Aunque gran parte del sitio combina estos elementos, un 18,1\% de las estructuras han sido edificadas exclusivamente en piedra y corresponden a aquellas dispersas en torno al conglomerado 1 y 2 . Los aparejos solo pudieron ser evaluados en aquellos recintos excavados por Rivera y su equipo (1995-1996) en una proporción cercana al $12 \%$ del total, dentro de lo cual se constata un $10,8 \%$ de muros con hiladas de adobes de barro y/o guijarros dispuestos horizontalmente o de forma sedimentaria.

Los paramentos por el interior presentan revestimiento del tipo enlucido de barro, aplicado en estado húmedo como queda demostrado en la impronta de diversas figuras decorativas u ornamentales en el conglomerado 1 . Un grabado antropomorfo y zoomorfo sobre un pilar fundacional ha sido registrado en la estructura 17 , próxima al conglomerado 2. En ciertas estructuras excavadas también se documentó el uso de grandes bloques o pilares verticales de piedra en doble hilera, a modo de fundaciones; aunque esta técnica no fue utilizada en estructuras circulares de menor tamaño (p. ej., conglomerado 2, estructuras 26 y 27, en Martindale 


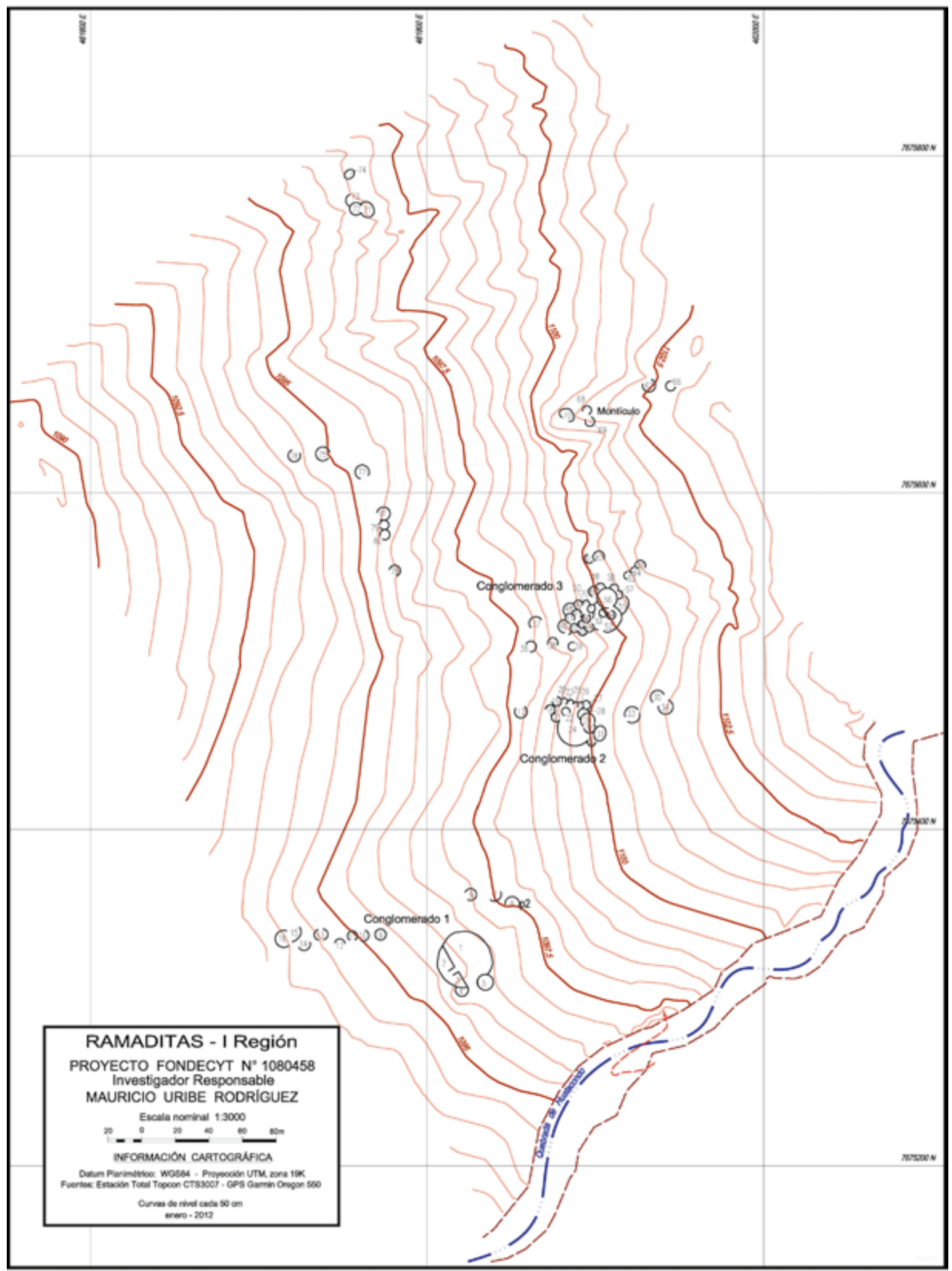

Figura 2a. Levantamiento topográfico aldea de Ramaditas. Figure 2a. Topographic map of the village of Ramaditas. 


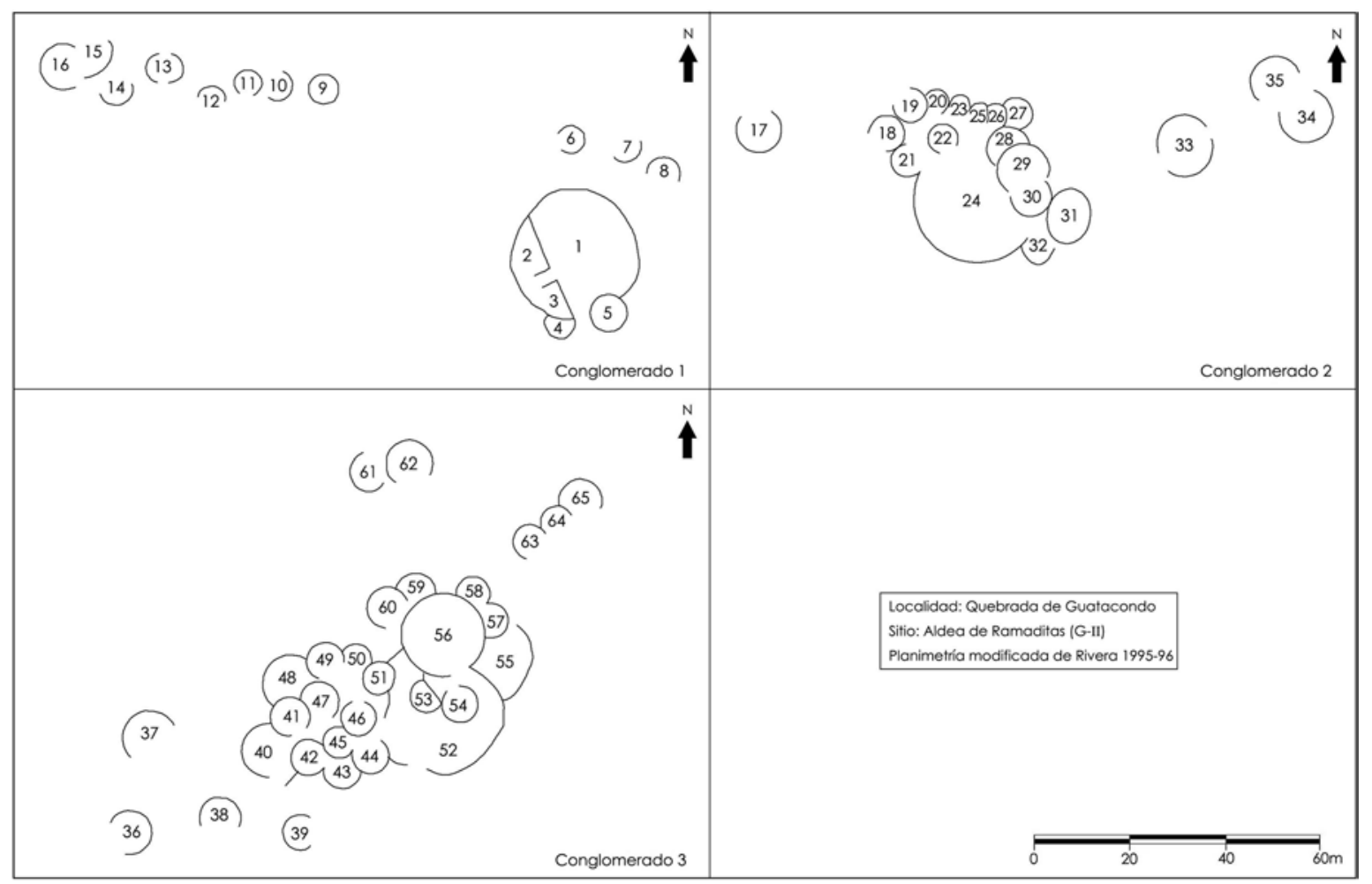

Figura 2b. Planimetría conglomerados 1,2 y 3 , aldea de Ramaditas.

Figure 2b. Planimetric map of conglomerates 1, 2 and 3, Ramaditas village.

Tabla 3. Distribución de forma de planta por sitio.

Table 3. Distribution of footprint shape, by site.

\begin{tabular}{|c|c|c|c|c|c|c|c|c|c|c|c|c|c|c|}
\hline$\stackrel{\circ}{\stackrel{⿹}{二}}$ & 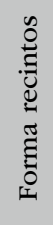 & 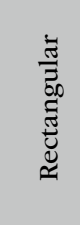 & 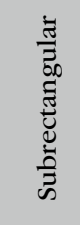 & 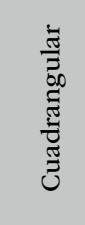 & 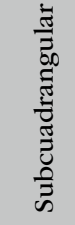 & $\frac{\vec{J}}{\tilde{J}}$ & 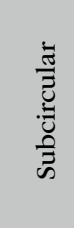 & 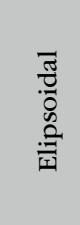 & $\begin{array}{l}\bar{\pi} \\
\frac{\pi}{0} \\
0 \\
0\end{array}$ & 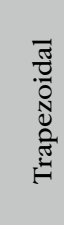 & 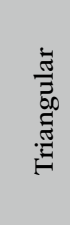 & 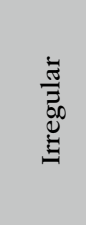 & $\frac{0}{z}$ & 胥 \\
\hline \multirow{2}{*}{ Ramaditas } & $\mathrm{n}$ & & 2 & 1 & & 14 & 9 & 5 & 24 & & & 28 & & 83 \\
\hline & $\%$ & & 2,40 & 1,20 & & 16,86 & 10,84 & 6,02 & 28,91 & & & 33,73 & & 100 \\
\hline \multirow{2}{*}{ Guatacondo } & $\mathrm{n}$ & 1 & 9 & 1 & 6 & 17 & 20 & & 21 & & & 98 & 4 & 177 \\
\hline & $\%$ & 0,56 & 5,08 & 0,56 & 3,38 & 9,60 & 11,29 & & 11,86 & & & 55,36 & 2,25 & 100 \\
\hline \multirow{2}{*}{ Pircas } & $\mathrm{n}$ & 26 & 6 & 12 & 2 & 122 & 57 & 173 & 10 & 7 & & 145 & 2 & 562 \\
\hline & $\%$ & 4,62 & 1,06 & 2,13 & 0,35 & 21,70 & 10,14 & 30,78 & 1,77 & 1,24 & & 25,80 & 0,35 & 100 \\
\hline \multirow{2}{*}{ Caserones } & $\mathrm{n}$ & 379 & 76 & 84 & 5 & 21 & 9 & & 9 & 4 & 2 & 53 & 3 & 645 \\
\hline & $\%$ & 58,75 & 11,78 & 13,02 & 0,77 & 3,25 & 1,39 & & 1,39 & 0,62 & 0,31 & 8,21 & 0,05 & 100 \\
\hline
\end{tabular}

2005: 147). En los muros expuestos pudo registrarse también un 13,3\% aplomado y medidas máximas de ancho en 0,6 $\mathrm{m}$ y de altura en $2,2 \mathrm{~m}$; este último registro tomando en cuenta la sección semisubterránea.
De los 76 vanos registrados, se aprecia una oscilación entre estructuras con cinco accesos (E.1) y un gran número con acceso único $(48,2 \%, \mathrm{~N}=40)$. También se documentaron pasillos de acceso, ventanas e improntas 
Tabla 4. Distribución de rangos de tamaño por sitio.

Table 4. Distribution of size ranges, by site.

\begin{tabular}{|c|c|c|c|c|c|c|c|c|c|}
\hline$\stackrel{\ominus}{\rightleftarrows}$ & 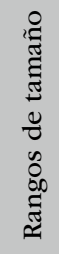 & 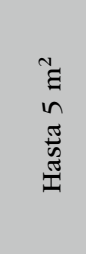 & $\begin{array}{l}\stackrel{I}{\Xi} \\
0 \\
\stackrel{-}{I} \\
\frac{1}{n}\end{array}$ & $\begin{array}{l}\text { İ } \\
\stackrel{2}{1} \\
\stackrel{1}{1} \\
\stackrel{-}{0}\end{array}$ & 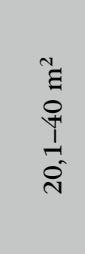 & 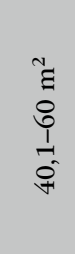 & 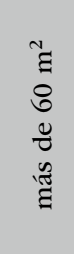 & $\stackrel{\circ}{\beth}$ & $\begin{array}{l}\bar{T} \\
0 \\
0\end{array}$ \\
\hline \multirow{2}{*}{ Ramaditas } & $\mathrm{n}$ & 13 & 22 & 28 & 9 & 4 & 7 & & 83 \\
\hline & $\%$ & 15,66 & 26,51 & 33,73 & 10,84 & 4,82 & 8,43 & & 100,00 \\
\hline \multirow{2}{*}{ Guatacondo } & $\mathrm{n}$ & 30 & 54 & 57 & 26 & 3 & 3 & 4 & 177 \\
\hline & $\%$ & 16,95 & 30,51 & 32,20 & 14,69 & 1,69 & 1,69 & 2,26 & 100,00 \\
\hline \multirow{2}{*}{ Pircas } & $\mathrm{n}$ & 338 & 90 & 76 & 32 & 12 & 14 & & 562 \\
\hline & $\%$ & 60,14 & 16,01 & 13,52 & 5,69 & 2,14 & 2,49 & & 100,00 \\
\hline \multirow{2}{*}{ Caserones } & $\mathrm{n}$ & 160 & 141 & 142 & 94 & 54 & 46 & 9 & 646 \\
\hline & $\%$ & 24,77 & 21,83 & 21,98 & 14,55 & 8,36 & 7,12 & 1,39 & 100,00 \\
\hline
\end{tabular}

de apoyo de vigas sobre los cabezales de los muros. Los elementos mejor representados en los vanos son las jambas, aunque también fueron registrados alféizares, en ciertos casos a modo de escalinatas, y dinteles compuestos de ramas paralelas, como ocurre con una ventana en la estructura 17. Es significativo el hecho de que no se encuentren dinteles en puertas y accesos a las estructuras (Martindale 2005).

\section{Guatacondo I o Aldea de Guatacondo}

La aldea Guatacondo-I se ubica a 1379 msnm, $300 \mathrm{~m}$ al sur de la quebrada homónima. Se emplaza junto a un curso inactivo, que se origina en la quebrada principal. La aldea de Guatacondo se encuentra sometida a intensos procesos de deflación y erosión eólica, debido a lo cual hemos registrado un total de 177 estructuras y no 183, como consigna Meighan en 1980. El sitio (UTM 7.678.869 N; 470.113 E, figs. 3a y b) conforma un asentamiento aglutinado con arquitectura pública de 0,78 ha de superficie total, lo cual indica una densidad edilicia de 227 estructuras por hectárea de terreno, la más alta de los cuatro sitios analizados. La superficie calculada intramuros es de $4215,1 \mathrm{~m}^{2}$, de tal manera que las estructuras ocupan más de la mitad del área interna de la aldea (FOS: 53,9\%, Tabla 1).

A nivel general, el registro de las formas de plantas expuesto en la Tabla 3 indica el predominio de recintos de muros curvos (circulares, subcirculares y ovales) con el 32,75\% de representación. Estructuras de planta irregular, cuya definición se dificulta por la presencia de acumulaciones de arena junto a los muros, constituyen más del 55\% de la muestra a lo que se suma un 2,3\% de estructuras sin información confiable. Se observa en Guatacondo una presencia menor de estructuras con muros formando ángulos, bajo el 10\%, con preponderancia de plantas subrectangulares (5,1\%, Tabla 3).

Los tamaños oscilan entre $0,2 \mathrm{~m}^{2}$ y $1838 \mathrm{~m}^{2}$, concentrados en su mayoría $(62,7 \%)$ en el segundo y tercer rango de tamaño $\left(5-20,1 \mathrm{~m}^{2}\right)$; mientras un $16,9 \%$ se ubica en el primer rango $\left(0-5,1 \mathrm{~m}^{2}\right)$ y de forma similar, con un $14,7 \%$, edificios con tamaños entre 20,1 y $40 \mathrm{~m}^{2}$. Destaca la escasa presencia de estructuras en el rango de mayor tamaño, sobre $60,1 \mathrm{~m}^{2}$, solo con un $1,7 \%$ de representación (Tabla 4). En consecuencia, en la aldea de Guatacondo vemos representado un espectro morfofuncional amplio, eminentemente doméstico de patrón circular y oval, nucleado en torno a una plaza central. Funcionalmente, se identifican espacios tipo bodega o depósitos, los cuales -junto a los pozos cavados-sugieren una importante capacidad de almacenaje del asentamiento; capacidad que se ve reflejada en los numerosos espacios de dormitorio, cocina y, probablemente, patios en torno a los cuales se organizan las viviendas. Respecto de las habitaciones, las que Meighan (1980) ubica acertadamente en el rango 4-20 $\mathrm{m}^{2}$, representarían aproximadamente 110 unidades del total $(\mathrm{N}=177)$. Considerando la baja ocurrencia de espacios de grandes dimensiones, utilizados evidentemente para la congregación de las unidades domésticas, es probable que el sitio no tenga una orientación ganadera como otros contemporáneos de tierras altas o más tardíos, como Caserones (Adán 


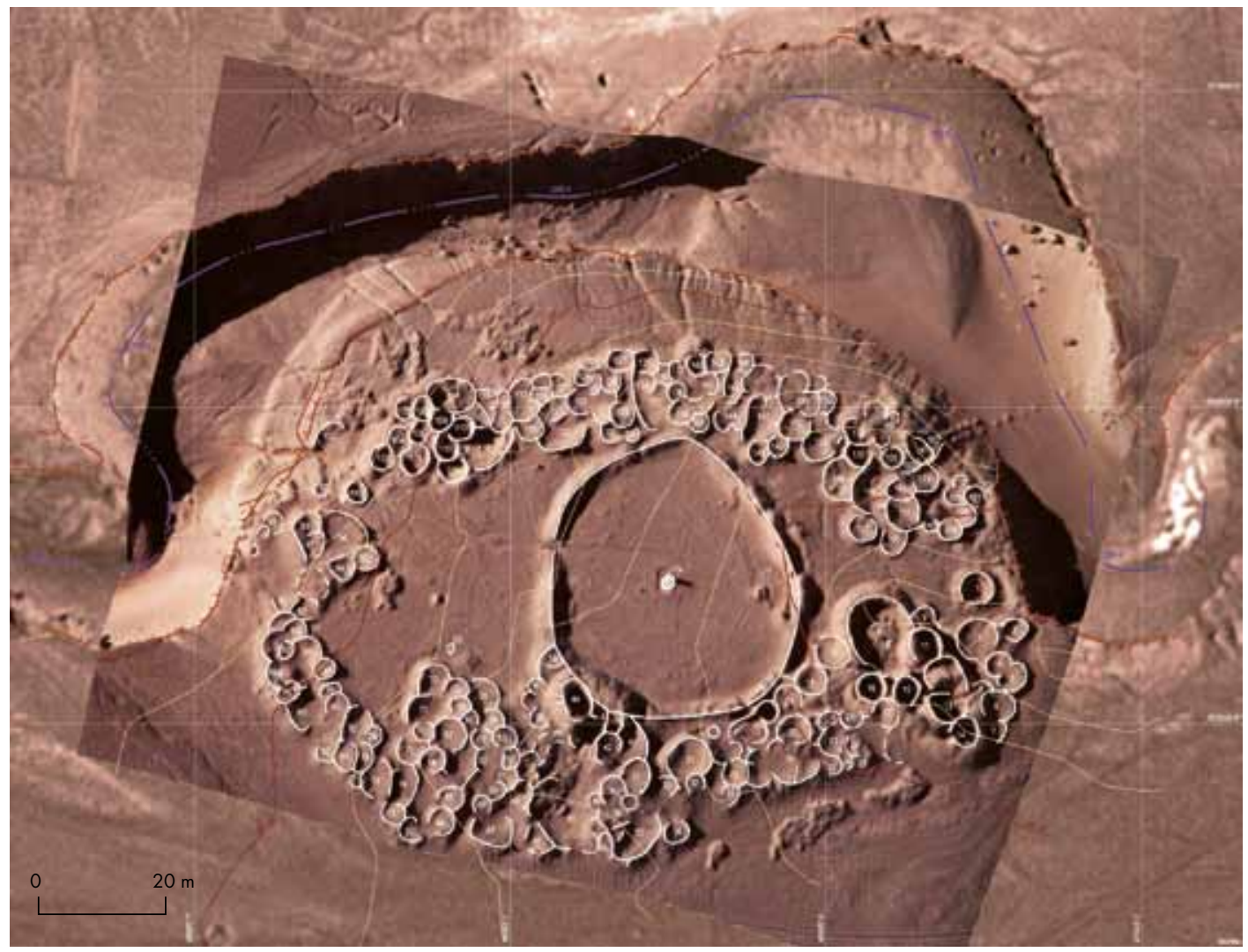

Figura 3a. Levantamiento topográfico de Guatacondo. Escala nominal 1:750.

Figure 3a. Topographic view of Guatacondo. Nominal scale 1:750.

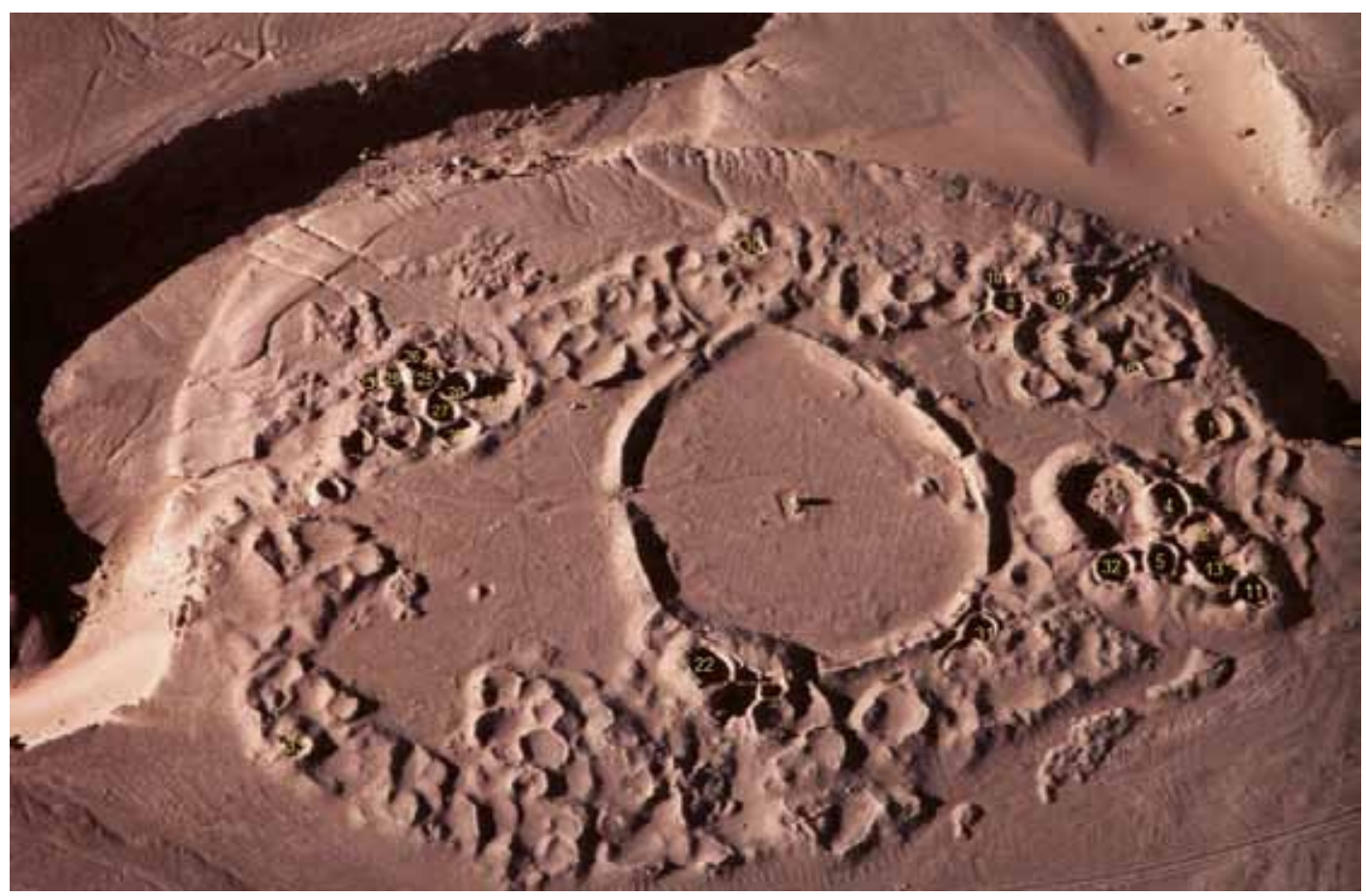

Figura 3b. Fotografía aérea aldea de Guatacondo y recintos excavados por Grete Mostny en 1970 (Anónimo, antes de 1970). Figure 3b. Aerial photograph of the village of Guatacondo with sites excavated by Grete Mostny in 1970 (Anonymous, pre-1970). 
et al. 2007). Espacios entre recintos, vías de circulación o espacios muertos producto del crecimiento de los conglomerados, también son evidentes en la presencia de espacios irregulares de diversos tamaños $(55,4 \%)$.

La información superficial que registramos en los paramentos indica el predominio de muros simples $(23,2 \%) y$, en una baja frecuencia, muros dobles y dobles con relleno con un 10,7\%. La baja visibilidad de los paramentos debido al relleno eólico de arena hace suponer que esta última proporción puede aumentar hacia las secciones inferiores de los muros. Respecto de los aparejos no es posible entregar información confiable por la misma razón, aunque en la plaza (E. 174) se aprecian paños sedimentarios y rústicos vinculados al tipo de factura de los adobones. La oscilación de los anchos de los muros se da entre 0,1 y 1,1 m (Tabla 2). Difícil definición presenta el registro de vanos dentro de la aldea, no obstante en el caso de la plaza central se registran cuatro accesos -sin elementos como jambas-, cuyos anchos oscilan entre 0,6 y 1,3 m, mientras sus orientaciones lo hacen entre $92^{\circ} \mathrm{E}, 133^{\circ} \mathrm{SE}, 167^{\circ} \mathrm{SE} y$ $290^{\circ} \mathrm{NW}$.

Al integrar la información provista por las excavaciones previas, los paramentos de adobe presentan alturas que oscilan entre 2,2 y 2,9 $\mathrm{m}$ y un ancho entre 0,2 y $1 \mathrm{~m}$, mientras las techumbres habrían sido elaboradas mediante un sistema de postación interior para el apoyo de vigas cubiertas con ramadas y, sobre ellas, una capa de barro fino (Meighan 1980: 102). En su base, los muros poseen grandes pilares de piedra dispuestos en intervalos y en ciertos casos bloques más pequeños dispuestos en las hiladas superiores, inclusive morteros reutilizados en los paramentos. Complementariamente, las excavaciones efectuadas en los sectores NW, NE y SE del asentamiento (Mostny 1980; Meighan 1980: Mapa 1:100), expusieron ciertas diferencias en el espesor de los muros y la cantidad de postes al interior de las viviendas, entre otras. Por ejemplo, el conglomerado en torno a la estructura 7 (SE) presenta mayor cantidad de muros dobles que aquel en torno a la estructura 25

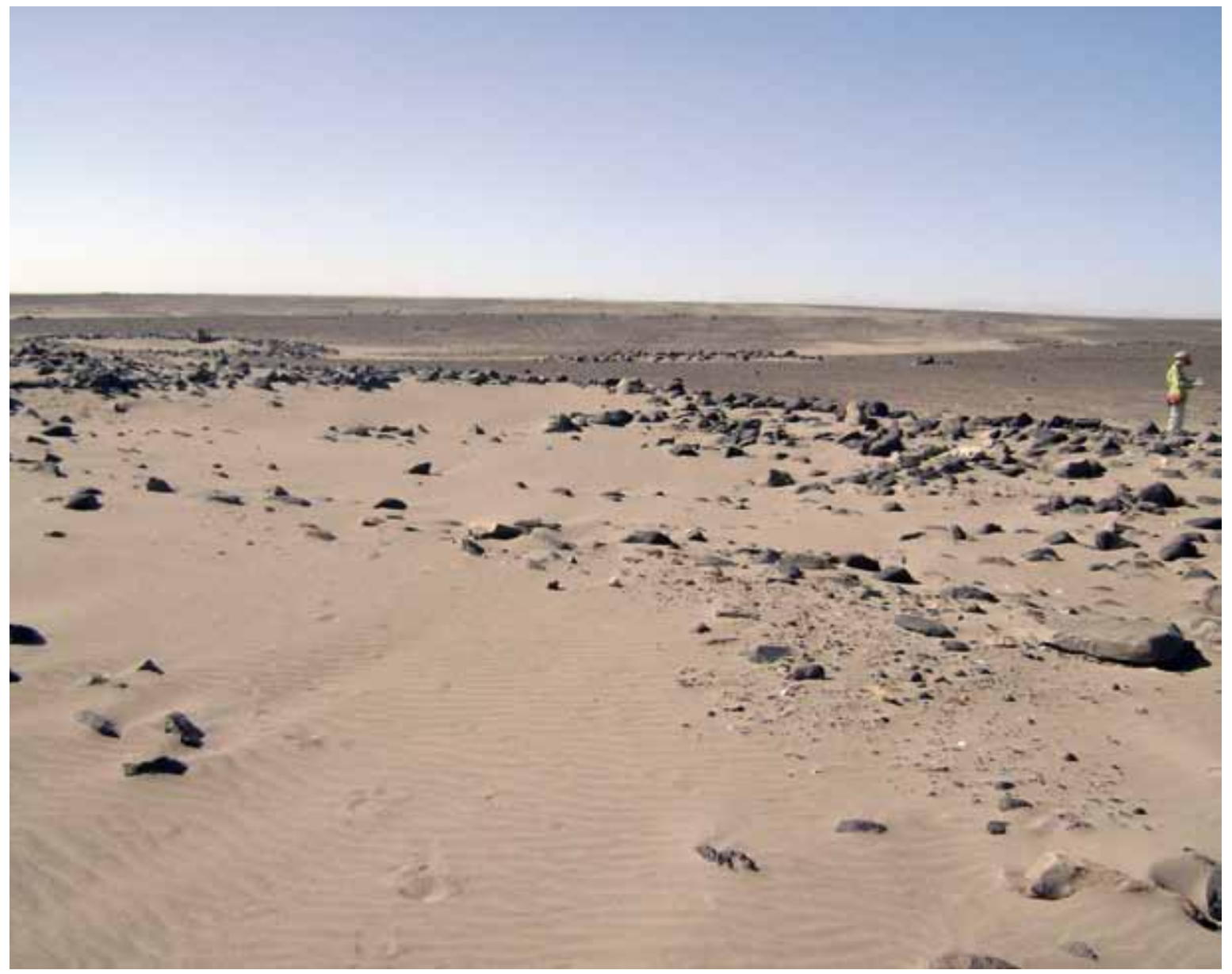

Figura 4a. Pircas: vista conglomerado en torno a estructura 184 (patio).

Figure 4a. Pircas: conglomerate view around structure 184 (patio). 


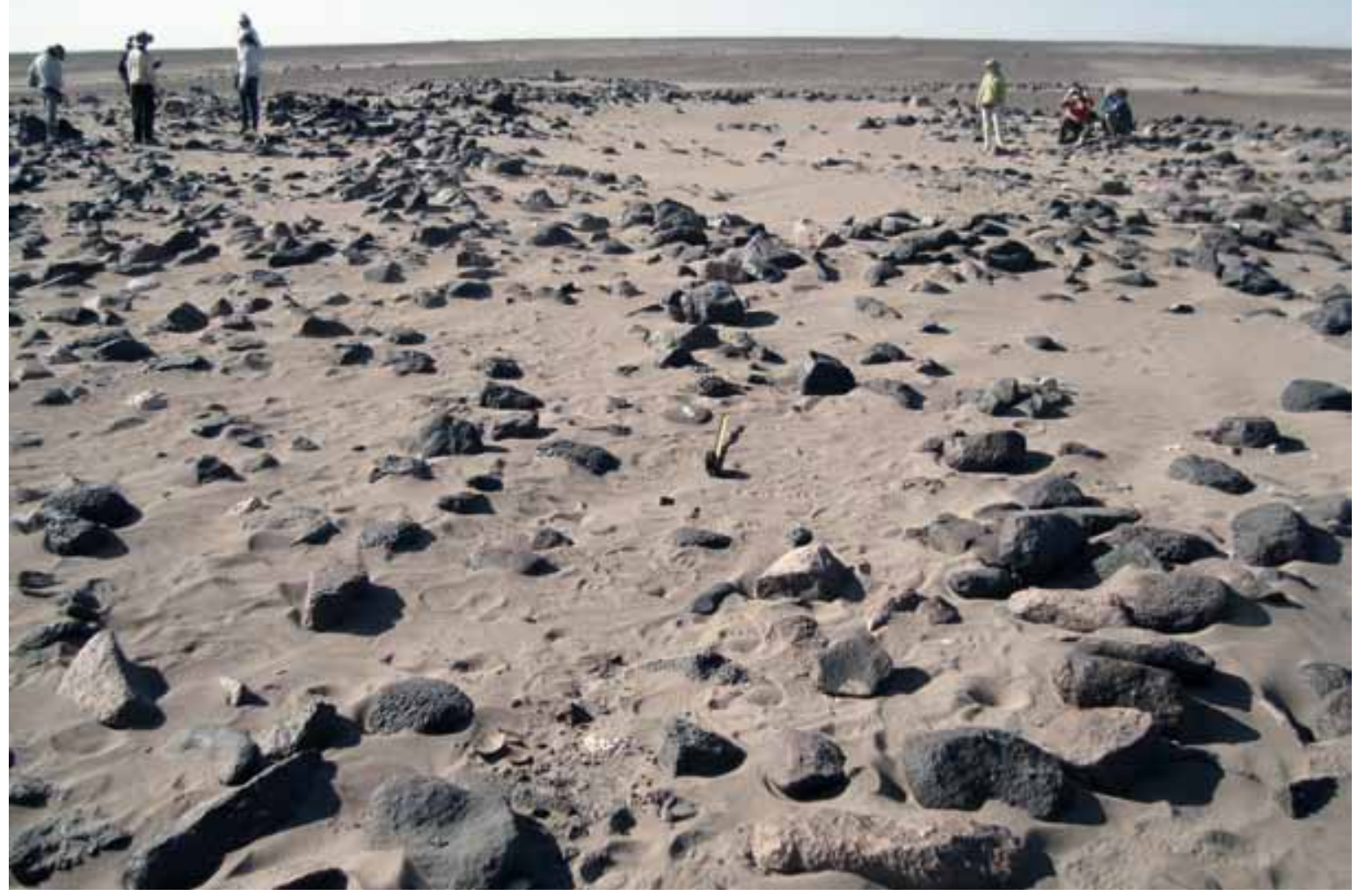

Figura 4b. Pircas: vista registro arquitectónico de conglomerado desde la estructura 193.

Figure 4b. Pircas: architectural register of conglomerate from structure 193.

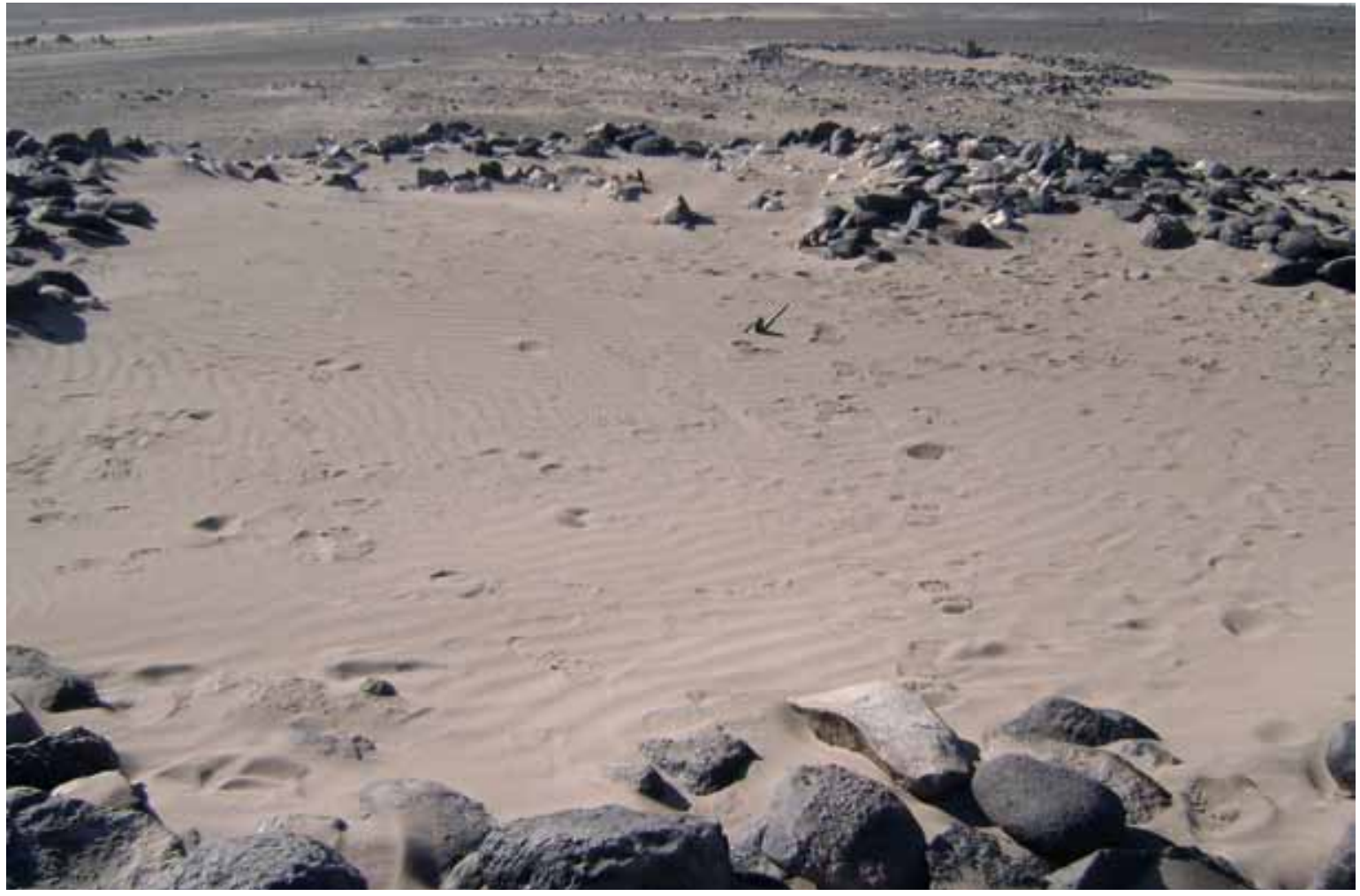

Figura 4c. Pircas: vista conglomerado en torno a estructura 207 (patio).

Figure 4c. Pircas: conglomerate view around structure 207 (patio). 
(NW); mientras en el sector NE los adobes son esféricos, probablemente moldeados con la mano, en el sector SE poseen forma rectangular de tamaños regulares. Al despejar completamente los pisos se pudo constatar en los sectores SE y NE que las habitaciones circulares poseían pisos interiores hundidos o semisubterráneos, fosos cavados en el calcáreo a modo de silos, cimientos de piedra (pilares) y sobre ellos adobes o, en menor medida, piedras más pequeñas en hiladas sedimentarias, postes de madera en las puertas a modo de jambas, en el centro y diametralmente opuestos, empleados para el soporte de la techumbre, posiblemente cónico y de totora (Mostny 1970, 1980). La estructura 12 es la única que posee una decena de pozos cavados en el piso, utilizados como silos o bodegas, y en sus paramentos muestra en el enlucido un rostro humano modelado similar a los de Ramaditas. También se aprecian improntas de manos y dedos sobre el revestimiento fresco que cubre los muros en ciertos sectores.

\section{Quebrada de Tarapacá}

\section{Campamento de Pircas}

Según el primer estudio efectuado, el sector más aglutinado del sitio Pircas (1230 msnm) se compone de un total de 56 conjuntos arqueológicos (Núñez 1982, 1984) donde sería posible apreciar estructuras habitacionales y de servicio, cementerios acotados, áreas ceremoniales delimitadas por muros periféricos, zonas de fosos de ofrendas en las proximidades a las estructuras habitacionales y en espacios abiertos, así como geoglifos elaborados como círculos de piedras con promontorio central, líneas paralelas, aserradas, líneas y círculos simples.

De manera más amplia, el asentamiento de Pircas (UTM 7.791.543 N; 441.170 E, figs. 4a, b y c) posee un patrón disperso de notable extensión. Nuestro registro arquitectónico fue realizado por transectas N-S, definiendo un polígono de alrededor de 90 ha donde se registran cientos de estructuras de distintas características, por lo cual es evidente la existencia de más de un componente arquitectónico en el lugar. Otro elemento notable es la intervisibilidad que se logra en el borde sur de Pircas con la aldea de Caserones, especialmente donde se concentran sus conglomerados más importantes (Núñez 1984: 168-169, figs. 1 y 2).

Considerando lo anterior, hemos identificado un total de 562 estructuras de piedra distribuidas sobre 89,89 ha, lo cual redunda en una alta dispersión del asentamiento con 6,3 estructuras por ha, la más baja de los sitios analizados. La inversión de trabajo calculada mediante la suma de las superficies interiores arroja un total de
$6594 \mathrm{~m}^{2}$, de tal manera que el índice FOS señala que un $0,7 \%$ de la superficie total del asentamiento ha sido destinada a recintos (Tabla 1 ).

Las estructuras de Pircas, en general, se presentan de manera aislada y en conglomerados con subdivisiones internas, además de aquellas que corresponden a los llamados "geoglifos", alineamientos perimetrales a otras estructuras, amontonamientos de piedras, parapetos semicirculares aislados o adosados a bloques mayores y, por último, depresiones con hileras laterales tapadas por relleno eólico de arena.

La distribución de las formas de planta (Tabla 3) indica el predominio de aquellas de muros curvos con un $64,4 \%$ de representación y especialmente de estructuras elipsoidales $(30,8 \%)$ y circulares $(21,7 \%)$. A continuación se registran estructuras de forma irregular con un $25,8 \%$, usualmente de difícil definición por el estado de conservación en el que se encuentran o el relleno de arena que las cubre. Por último, y en una baja frecuencia, se encuentran los espacios de factura rectangular, cuadrangular y sus derivados, los cuales alcanzan un 8,2\% del total, con predominio de aquellas rectangulares, cuya frecuencia no supera el 5\%.

La clasificación de los tamaños (Tabla 4) permite apreciar una significativa presencia de pequeñas estructuras de menos de $5 \mathrm{~m}^{2}$, las cuales alcanzan una frecuencia de $60,1 \%$, posiblemente sobrerrepresentada por la presencia de varias ocupaciones transitorias de diversos períodos en el lugar. Las estructuras ubicadas en el rango de espacios domésticos o asociados a estos, entre 5,1 y $20 \mathrm{~m}^{2}$, alcanzan un 29,5\%. A continuación se encuentra un pequeño conjunto de estructuras medianas y grandes $\left(20,1-60 \mathrm{~m}^{2}\right)$ que pudieron servir de espacios habitacionales, patios o corrales. Finalmente, un 2,5\% de espacios muy grandes identificados como recintos de uso comunal o público, alineamientos perimetrales y geoglifos. Tomando en cuenta el tramo más confiable para espacios domésticos, usualmente ubicado entre 5,1 y $20 \mathrm{~m}^{2}$, es posible estimar un total de 166 viviendas, las cuales evidentemente podrían ser más si se consideran aquellas destinadas a residencias o pernocte transitorio a modo de refugios (sensu Niemeyer \& Rivera 1983), ubicadas en el tramo bajo los $5 \mathrm{~m}^{2}$.

La información obtenida del registro de paramentos (Tabla 2) indica el predominio de hileras simples de piedra en un $41,5 \%$ de los casos, seguido de muros dobles y dobles con relleno que en conjunto totalizan un 15,3\%. Los aparejos han sido elaborados normalmente de forma rústica, aunque solo se pudo registrar este elemento de diseño en un 22,8\% de las estructuras. Las excavaciones practicadas por Núñez (1984) y nuestro equipo detectaron el uso de fundaciones a modo de pilares o 
grandes bloques de piedra dispuestos horizontalmente. El uso de mortero solo se observa en ciertos recintos, no obstante lo común es percibir el relleno de los muros dobles, saliendo entre los bloques de piedra de mayor tamaño. El ancho máximo registrado en los muros es 1,38 m, mientras el alto máximo es de 0,8 m. Los vanos registrados son difíciles de definir si no ocurren excavaciones sistemáticas futuras. No obstante, de acuerdo a la presencia de jambas pudieron ser identificados ocho accesos, ubicados de forma individual como dos vanos en ciertas estructuras. Sus anchos varían entre 0,5 y 1,1 $\mathrm{m}$ y sus altos pueden alcanzar máximo 0,4 $\mathrm{m}$.

\section{Aldea de Caserones}

Los estudios dirigidos por nuestro equipo a partir del año 2005 se han propuesto revaluar la arquitectura del asentamiento (Núñez 1966, 1982), mediante una metodología que permita comparaciones con otros sitios del Período Formativo. De acuerdo a nuestros primeros resultados describimos la aldea de Caserones (UTM 7.790.970 N;
$441.400 \mathrm{E}$, figs. $5 \mathrm{a}$ y b), ubicada a $1290 \mathrm{msnm}$, como un conjunto edificado compuesto de 636 estructuras sobre una superficie de $37500 \mathrm{~m}^{2}$, lo que señalaba un patrón aglomerado de 170 recintos por hectárea (Adán et al. 2007). La excavación de diversos recintos como la evaluación de las diversas vías de circulación que el sitio presenta ha aumentado el número total de estructuras a 645 (Pellegrino 2011), por lo cual la densidad edilicia se elevaría sobre 172,3 estructuras por ha. La superficie acumulada entre todas las estructuras indica que la inversión de trabajo ascendió hasta $15.996 \mathrm{~m}^{2}$, por lo cual la ocupación efectiva de la superficie de la aldea ha ocurrido en un porcentaje cercano a 43\% (Tabla 1).

En términos estrictos, el asentamiento está formado por tres macrosectores o grandes conglomerados que se van aglutinando por muros contiguos o colindantes. En el extremo NE, separado por una vía de circulación, se define un conjunto compuesto por los recintos 1 al 83 , y el segundo, por los recintos 84 al 179. Un tercer conglomerado es el que se localiza hacia el W del sitio definido por un sector central sumamente aglutinado

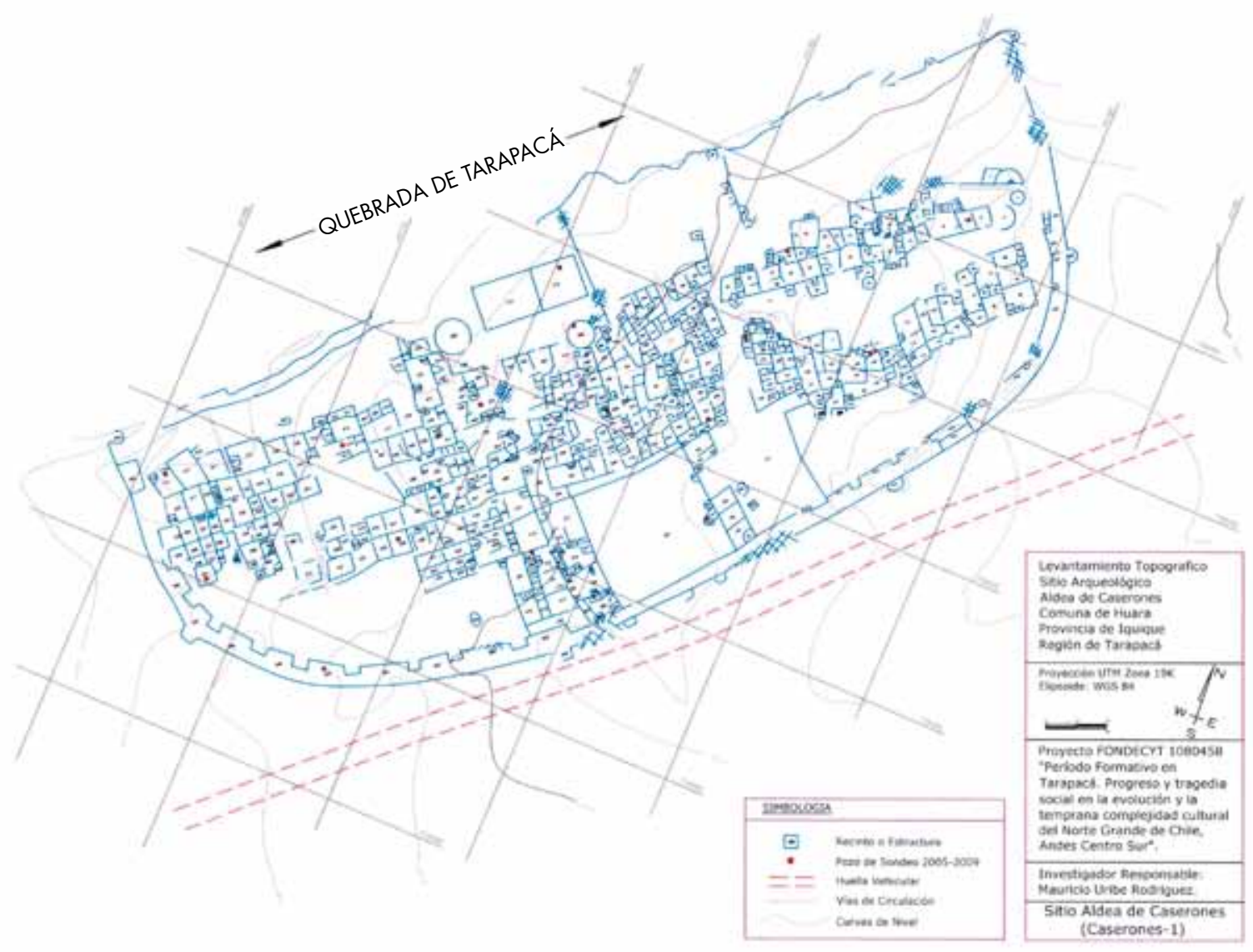

Figura 5a. Levantamiento topográfico aldea de Caserones.

Figure 5a. Topographic map of Caserones village. 


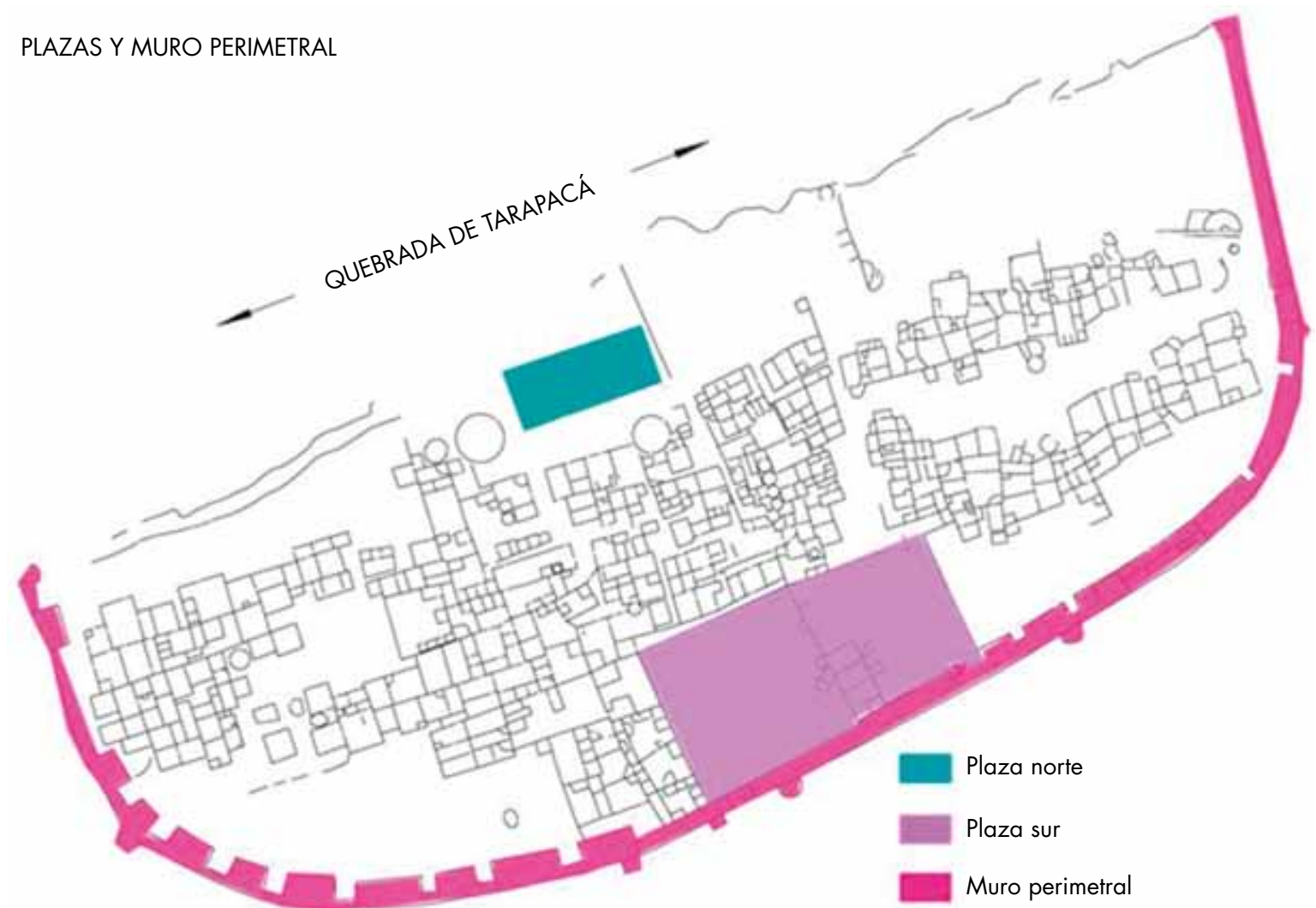

Figura 5b. Planimetría con plazas y muro perimetral de Caserones (Pellegrino 2011).

Figure 5b. Planimetric map of Caserones, with plazas and perimeter wall (Pellegrino 2011).

conformado por los recintos 180 al 351; un sector contiguo, con una disposición más longitudinal al sitio, entre los recintos 354 y 504 y, por último, un sector organizado luego de una formación de túmulos, recintos 511 al 593, el cual se proyecta hasta empalmar con el muro perimetral (Adán et al. 2007). Para efectos del presente trabajo hemos propuesto una división más detallada de tales grandes conglomerados, mediante el registro de las trabas y apoyos entre muros con el objeto de evaluar la inversión de trabajo implicada en al menos siete conglomerados menores (fig. 6, ver también más adelante Tabla 9).

A nivel global, las formas de planta dominantes son la rectangular, subrectangular y cuadrangular, presentando un $84,6 \%$ de frecuencia acumulada. Le siguen las plantas irregulares, con un $8,2 \%$ de ocurrencia, y tan solo con un $6 \%$, estructuras de planta circular o de muros curvos, las cuales pese a su escasa frecuencia son interesantes por su clara definición y diferencia con el conjunto en general (Tabla 3). Respecto de los tamaños (Tabla 4), el registro acusa una importante variabilidad: la mayor cantidad de recintos presenta dimensiones entre 5,1 y $20 \mathrm{~m}^{2}$ con un $43,8 \%$, seguido por recintos menores a $5 \mathrm{~m}^{2}$, cuya frecuencia alcanza el 24,8\% del total. Entre 20 y $40 \mathrm{~m}^{2}$ se agrupan 148 estructuras que constituyen un 22,9\% de la muestra, al igual como ocurre con aquellos de más de $40 \mathrm{~m}^{2}$, que representan el 7,1\% del asentamiento. La comparación de los tres principales conglomerados de la aldea señala una importante uniformidad funcional en la configuración final del asentamiento (Adán et al. 2007). Considerando la frecuencia de estructuras entre 5,1 y $20 \mathrm{~m}^{2}$, se infiere un mínimo de unidades habitacionales cercano a 283 estructuras.

Los paramentos se construyeron en bloques de caliche o anhidrita (Tabla 2), con inclusiones ocasionales de bloques seleccionados de andesita y basalto en la sección inferior de muros, a modo de fundaciones (E.37 y 344). Un dato interesante es la presencia de grandes piedras como pilares estructurales, así como una profusa utilización de postes de madera configurando parte integral de los muros, rasgo presente en los diversos conjuntos de la aldea (p. ej., E.6, 114, 288 y 598). Se observan muros simples $(37,9 \%)$, dobles y dobles con rellenos que alcanzan una proporción algo mayor de $40,2 \%$. Entre estos últimos dominan los muros dobles con relleno $(39,9 \%)$, indicación de una mayor inversión 


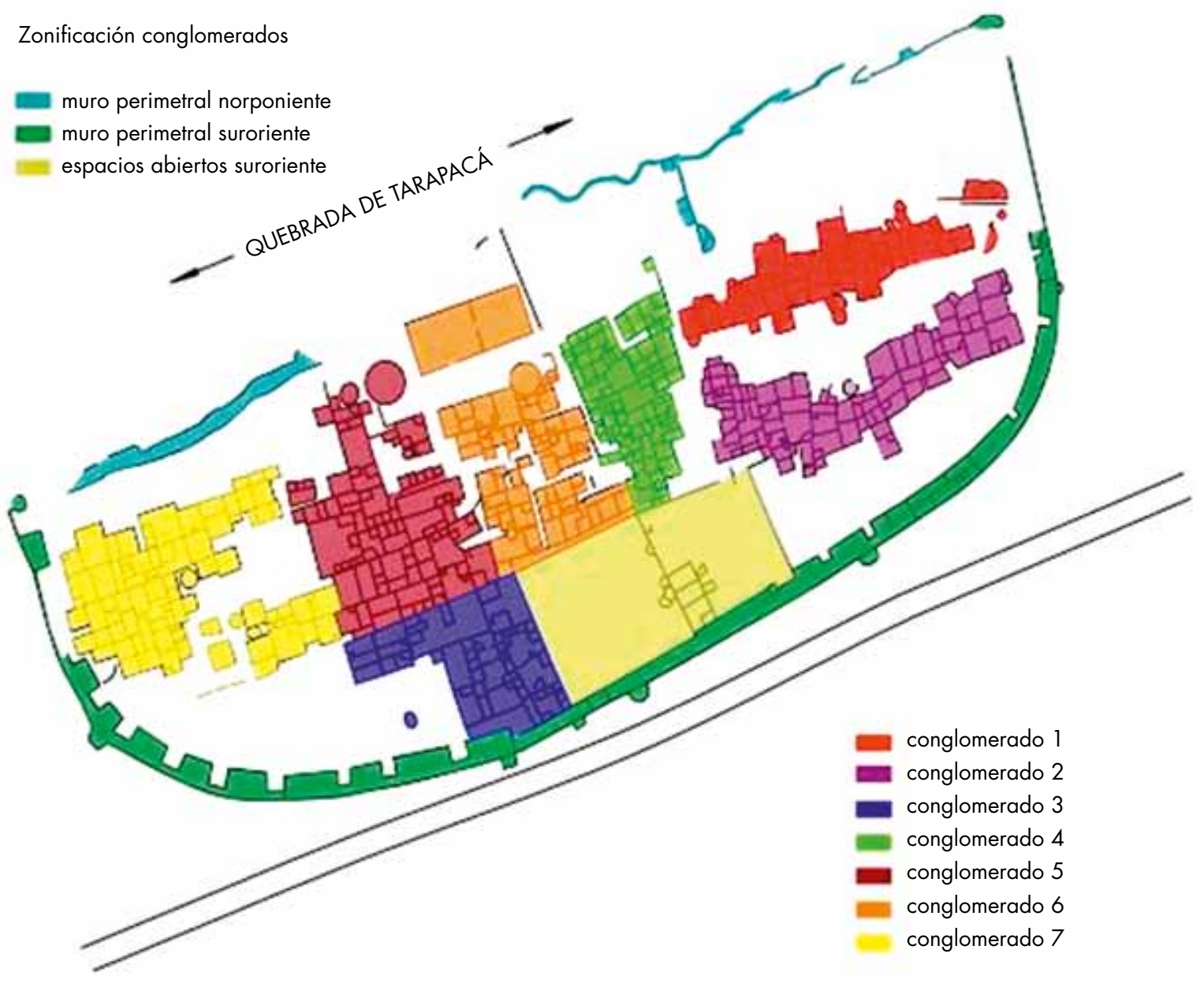

Figura 6. Propuesta de sectorización superficial de los conglomerados de Caserones (Pellegrino 2011).

Figure 6. Proposed sectors of Caserones conglomerates (Pellegrino 2011).

de energía en la edificación de ciertos recintos. Sobre el aparejo, ellos tienden a ser sedimentarios $(24,6 \%)$ y rústicos $(19,2 \%)$ en frecuencias cercanas, con una importante ocurrencia de muros con revoque de barro o revestidos $(14,5 \%)$, característica que podría ser aun mayor considerando las condiciones de conservación que afectan este rasgo. El ancho de los muros oscila entre 0,1 y $1,6 \mathrm{~m}$, en tanto que las alturas señalan un máximo de $1,98 \mathrm{~m}$. El registro de vanos, solo considerando como seguros aquellos que presentan elementos como jambas, alféizares y dinteles, elevan el número de unidades a 112, entre las que se cuentan accesos, ventanas, hornacinas y posiblemente hoyos de postes perpendiculares a los muros, los cuales distorsionan la muestra general.

\section{DISCUSIÓN}

\section{Sobre los tipos de unidades domésticas}

Un primer aspecto que nos interesa destacar es la edificación de tipos preferentes de unidades domésticas en los sitios, donde los inmuebles y los espacios de la vida cotidiana conforman un escenario de experimentaciones ambiciosas y altamente visibles. Los espacios, interiores, fachadas y las techumbres son enriquecidos inclusive con decoraciones en paredes y postes en el caso de Ramaditas y Guatacondo. Junto con la extracción, el uso y el modelamiento del barro, ocurre la extracción masiva y desbaste de costras salinas como la anhidrita o caliche en Caserones y mínimamente en Pircas (sector nuclear). La selección de materiales constructivos por tamaño, color, durabilidad y propiedades térmicas, es 
especialmente importante en los guijarros y pilares fundacionales monolíticas en Pircas; de igual modo que en la extracción de anhidrita (caliche) o en la selección de maderas para postes y/o soportes estructurales de muros y techumbres.

En este aspecto, las innovaciones arquitectónicas referidas distinguen a Ramaditas y Pircas, donde los complejos residenciales parecen sostener una disputa reforzada por una cuidada distancia entre sí. Los agregados familiares en estos asentamientos mediante espacios domésticos pareados e interconectados -señal de cohabitación de familias extensas, pequeños clanes o segmentos de linajes, como usualmente los entendemos-, sugieren que los cambios en la estructura de parentesco responden no solo a un crecimiento demográfico o al sedentarismo.

La conformación de ambientes más protegidos ocurre no exenta de tensiones, puesto que se ha establecido un pacto político de vida gregaria. Las familias invierten en espacios domésticos sólidos, de gran volumen, trabajan cuidadamente en el acabado y enlucido de los muros, urden techumbres que requieren postación interna y periférica, cantidades enormes de vegetales y amarras, vigas, etc. En Pircas esta situación se percibe en la disposición de enormes hiladas de pilares de piedra en conglomerados de esquinas curvadas (Núñez 1982), lo cual sugiere un intenso diálogo y competencia en el vecindario, el cual considera también una restauración del pasado "Arcaico" mediante el uso de prácticas constructivas en piedra. Dichos elementos constructivos y de diseño, propios de la tradición temprana (Adán \& Urbina 2007), continúan por siglos siendo utilizados en otros asentamientos de la región. En esta medida, haciendo referencia, o no, al pasado y al presente, la arquitectura doméstica aglutinada vincula, iguala o distingue a las familias a nivel intrasitio e intersitio.

Estas consideraciones pueden ser discutidas cruzando la información de tamaño y forma proveniente del registro de planta. Tomando en cuenta los antecedentes arcaicos que presenta la quebrada de Tarapacá, vemos primero en Pircas una clara manifestación de los patrones constructivos conocidos para esta época, presentes tanto en la costa desértica como en las tierras altas circumpuneñas (Adán \& Urbina 2007; Urbina et al. 2011, 2012). De acuerdo a la distribución de formas según rangos de tamaño (Tabla 5), observamos un patrón constante de planta, principalmente, elipsoidal (1249 $\mathrm{m}^{2}$ construidos) y circular (937 $\mathrm{m}^{2}$ construidos) para estructuras bajo los $5 \mathrm{~m}^{2}$. En aquellas que probablemente fueron

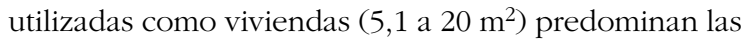
construcciones elipsoidales $(\mathrm{N}=67)$ por sobre las circulares $(\mathrm{N}=19)$. Es probable que exista un tipo de unidad doméstica de planta rectangular representada en menor medida $(\mathrm{N}=11)$ y en una cantidad significativa, plantas que no han podido ser adscritas a una forma definida (irregulares, entre 5,1 y $20 \mathrm{~m}^{2}$; $\mathrm{N}=45$ ).

En Ramaditas -sitio que probablemente inaugura la tradición arquitectónica en barro en el ámbito oasis y quebradas de Tarapacá-, la preferencia por formas de muros curvos, circulares y ovoidales es más manifiesta que en Pircas, no obstante esta diferencia puede ser poco significativa debido a que las estructuras en general se hallan cubiertas de arena hasta sus cabezales. Además, en Ramaditas el uso de la piedra se restringe "conmemorativamente" a las fundaciones, con la típica configuración de pilares verticales empotrados en el suelo sobre el que se traban adobones de barro o guijarros en hiladas sedimentarias. Ambos sitios también comparten el uso de viviendas semisubterráneas de muros curvos. Espacios pequeños (menos de $5,1 \mathrm{~m}^{2}$ ) en Ramaditas utilizan preferentemente plantas subcirculares $(46,2 \%)$ y ovoidales $(23,1 \%)$ (Tabla 6 ). En el segundo y tercer rango $\left(5,1\right.$ a $\left.20 \mathrm{~m}^{2}\right)$, hipotéticamente asociado a actividad residencial, observamos una tendencia similar con una mayoría de plantas ovoidales $(\mathrm{N}=16)$ y circulares $(\mathrm{N}=9)$, así como una pequeña cantidad de viviendas de planta elipsoidal $(\mathrm{N}=4)$ y subcircular $(\mathrm{N}=3)$. En los edificios de mayor tamaño se mantiene la presencia de este binomio oval-circular, al menos entre 40,1 y $60 \mathrm{~m}^{2}$ y con predominancia del primer tipo de planta. En términos generales, el patrón circular acumula la principal cantidad de $\mathrm{m}^{2}$ construidos $\left(785 \mathrm{~m}^{2}\right)$, mientras las plantas ovoidales $\left(356 \mathrm{~m}^{2}\right)$ y elipsoidales $\left(200 \mathrm{~m}^{2}\right)$ le siguen con cantidades menores.

La aldea de Guatacondo, la cual manifiesta clara relación con Ramaditas en cuanto al profuso manejo del barro y sus propiedades plásticas y estéticas, ejemplifica un patrón arquitectónico también apegado a los cánones circulares y ovoidales como consta en las superficies edificadas con estas formas (194 y $2109 \mathrm{~m}^{2}$ ) respectivamente. En el caso de pequeñas estructuras (menos de $5 \mathrm{~m}^{2}$ ) se han privilegiado plantas subcirculares en un 43,33\% de los casos, usualmente para cerrar espacios entre dos estructuras de mayor tamaño. En el segundo y tercer rango (5,1-20 $\left.\mathrm{m}^{2}\right)$ plantas circulares y subcirculares dominan $(\mathrm{N}=22)$ frente a sus símiles de planta oval ( $\mathrm{N}=12)$, no obstante, hacia los rangos de mayor tamaño, las estructuras ovoidales son dominantes (Tabla 7). La ocurrencia divergente de unidades espaciales de planta subrectangular es un rasgo que diferencia sutilmente a Guatacondo de Ramaditas; con un total edificado de $103 \mathrm{~m}^{2}$ y con especial representación en el segundo rango de 5,1 a $10 \mathrm{~m}^{2}$ en el que empata a las plantas circulares con un $11,1 \%$, lo cual podría argumentarse 
Tabla 5. Pircas: distribución de formas de planta según rangos de tamaño. Table 5. Pircas: distribution of footprint shape by size ranges.

\begin{tabular}{|c|c|c|c|c|c|c|c|c|c|c|c|c|c|c|}
\hline Pircas & $\begin{array}{c}0-5,1 \\
\mathrm{~m}^{2}\end{array}$ & $\%$ & $\begin{array}{c}5-10,1 \\
\mathrm{~m}^{2}\end{array}$ & $\%$ & $\begin{array}{c}10- \\
20,1 \\
\mathrm{~m}^{2}\end{array}$ & $\%$ & $\begin{array}{c}20- \\
40,1 \\
\mathrm{~m}^{2}\end{array}$ & $\%$ & $\begin{array}{c}40- \\
60,1 \\
\mathrm{~m}^{2}\end{array}$ & $\%$ & $\begin{array}{c}+60,1 \\
\mathrm{~m}^{2}\end{array}$ & $\%$ & Total & $\begin{array}{c}\text { Superficie } \\
\mathrm{m}^{2}\end{array}$ \\
\hline Rectangular & 7 & 2,07 & 4 & 4,44 & 7 & 9,21 & 4 & 12,50 & & & 4 & 28,57 & 26 & 763,36 \\
\hline Subrectangular & 2 & 0,59 & 1 & 1,11 & & & 1 & 3,13 & 2 & 16,67 & & & 6 & 128,73 \\
\hline Cuadrangular & 5 & 1,48 & 2 & 2,22 & 1 & 1,32 & 1 & 3,13 & 2 & 16,67 & 1 & 7,14 & 12 & 349,12 \\
\hline Subcuadrangular & 2 & 0,59 & & & & & & & & & & & 2 & 4,99 \\
\hline Circular & 90 & 26,63 & 13 & 14,44 & 6 & 7,89 & 8 & 25,00 & 2 & 16,67 & 3 & 21,43 & 122 & 937,74 \\
\hline Subcircular & 46 & 13,61 & 6 & 6,67 & 4 & 5,26 & 1 & 3,13 & & & & & 57 & 194,04 \\
\hline Elipsoidal & 98 & 28,99 & 40 & 44,44 & 27 & 35,53 & 6 & 18,75 & 1 & 8,33 & 1 & 7,14 & 173 & 1249,72 \\
\hline Oval & 4 & 1,18 & 4 & 4,44 & 2 & 2,63 & & & & & & & 10 & 59,79 \\
\hline Trapezoidal & 3 & 0,89 & & & 4 & 5,26 & & & & & & & 7 & 54,32 \\
\hline \multicolumn{15}{|l|}{ Triangular } \\
\hline Irregular & 79 & 23,37 & 20 & 22,22 & 25 & 32,89 & 11 & 34,38 & 5 & 41,67 & 5 & 35,71 & 145 & 2852,27 \\
\hline $\mathrm{n} / \mathrm{o}$ & 2 & 0,59 & & & & & & & & & & & 2 & \\
\hline Total & 338 & 100,00 & 90 & 100,00 & 76 & 100,00 & 32 & 100,00 & 12 & 100,00 & 14 & 100,00 & 562 & \\
\hline Superficie $\mathrm{m}^{2}$ & 755,17 & & 657,58 & & 1056,03 & & 917,34 & & 592,32 & & 2615,67 & & & 6594,13 \\
\hline
\end{tabular}

Tabla 6. Ramaditas: distribución de formas de planta según rangos de tamaño. Table 6. Ramaditas: distribution of footprint shapes by size ranges.

\begin{tabular}{|c|c|c|c|c|c|c|c|c|c|c|c|c|c|c|}
\hline Ramaditas & $\begin{array}{c}0-5,1 \\
\mathrm{~m}^{2}\end{array}$ & $\%$ & $\begin{array}{c}5-10,1 \\
\mathrm{~m}^{2}\end{array}$ & $\%$ & $\begin{array}{c}10- \\
20,1 \\
\mathrm{~m}^{2}\end{array}$ & $\%$ & $\begin{array}{c}20- \\
40,1 \\
\mathrm{~m}^{2}\end{array}$ & $\%$ & $\begin{array}{c}40- \\
60,1 \\
\mathrm{~m}^{2}\end{array}$ & $\%$ & $\begin{array}{c}+60,1 \\
\mathrm{~m}^{2}\end{array}$ & $\%$ & Total & $\begin{array}{c}\text { Superficie } \\
\mathrm{m}^{2}\end{array}$ \\
\hline \multicolumn{15}{|l|}{ Rectangular } \\
\hline Subrectangular & & & 2 & 9,09 & & & & & & & & & 2 & 14,43 \\
\hline Cuadrangular & 1 & 7,69 & & & & & & & & & & & 1 & 2,90 \\
\hline \multicolumn{15}{|l|}{ Subcuadrangular } \\
\hline Circular & 1 & 7,69 & 5 & 22,73 & 4 & 14,29 & 1 & 11,11 & 1 & 25,00 & 2 & 28,57 & 14 & 785,42 \\
\hline Subcircular & 6 & 46,15 & 3 & 13,64 & & & & & & & & & 9 & 42,42 \\
\hline Elipsoidal & & & 1 & 4,55 & 3 & 10,71 & & & & & 1 & 14,29 & 5 & 200,88 \\
\hline Oval & 3 & 23,08 & 6 & 27,27 & 10 & 35,71 & 4 & 44,44 & 1 & 25,00 & & & 24 & 356,04 \\
\hline \multicolumn{15}{|l|}{ Trapezoidal } \\
\hline \multicolumn{15}{|l|}{ Triangular } \\
\hline Irregular & 2 & 15,38 & 5 & 22,73 & 11 & 39,29 & 4 & 44,44 & 2 & 50,00 & 4 & 57,14 & 28 & 967,36 \\
\hline \multicolumn{15}{|l|}{$\mathrm{n} / \mathrm{o}$} \\
\hline Total & 13 & 100,00 & 22 & 100,00 & 28 & 100,00 & 9 & 100,00 & 4 & 100,00 & 7 & 100,00 & 83 & \\
\hline Superficie $\mathrm{m}^{2}$ & 44,98 & & 172,36 & & 385,82 & & 239,75 & & 199,70 & & 1326,86 & & & 2369,47 \\
\hline
\end{tabular}


como cierta tendencia bimodal en las viviendas más pequeñas dentro de la aldea (Tabla 7 ).

En Caserones, por último, se aprecia un notable alejamiento de los tipos de edificios residenciales señalados previamente; no solo basado en la enorme inversión arquitectónica en estructuras de planta rectangular $\left(11.205 \mathrm{~m}^{2}\right)$, cuadrangular $\left(1746 \mathrm{~m}^{2}\right)$ y subrectangular $\left(1458 \mathrm{~m}^{2}\right.$ ) (Tabla 8), sino también en una renovación e innovación tecnológica en cuanto a la utilización del caliche, ausencia de plantas semisubterráneas y el uso diestro de los sistemas de postación periférica, ahora empotrados en los muros para techumbres del tipo ramada (True 1980). Aquí el dominio de las plantas rectangulares y cuadrangulares se evidencia a lo largo de todos los rangos de tamaño, lo cual implica asumir que estas formas fueron utilizadas en todo el espectro funcional que el asentamiento contempló a través de su larga historia ocupacional (True 1980; Núñez 1982, 2006; Adán et al. 2007).

Particularmente en los rangos asignados a funciones domésticas $\left(5,1-20 \mathrm{~m}^{2}\right)$ las estructuras rectangulares $(\mathrm{N}=186)$ superan holgadamente a aquellas cuadrangulares $(\mathrm{N}=27)$ e inclusive a plantas subrectangulares $(\mathrm{N}=33)$. Observadas a modo de tendencias, las estructuras cuadrangulares han sido privilegiadas para usos más bien de almacenaje o bodega (Adán et al. 2007), decreciendo en forma constante hacia los rangos de mayor tamaño. Mientras los edificios rectangulares describen una curva ascendente a partir del primer rango (menor a $5 \mathrm{~m}^{2}$ ) con un $48,13 \%$, alcanzan su primer peak en el tercer rango $\left(10,1-20 \mathrm{~m}^{2}\right)$ con un $66,9 \% \mathrm{y}$, luego de un descenso leve, retoman un segundo peak en el último rango (mayores a $60 \mathrm{~m}^{2}$ ), que inclusive se eleva sobre el 71\% (Tabla 9). Es necesario no pasar por alto cantidades menores de espacios posiblemente domésticos de planta circular $(\mathrm{N}=4)$ y ovoidal $(\mathrm{N}=3)$, registrados en el segundo y tercer rango de tamaño de la Tabla 8 . En términos globales, ambos formatos comprometen 263 y $108 \mathrm{~m}^{2}$ edificados del total, respectivamente, lo cual permitiría argumentar cierta variabilidad mínima dentro del conjunto, aunque no sabemos si aquello tiene connotaciones cronológicas, o si se vincula con funciones distintas a las residenciales (p. ej., almacenaje a gran escala).

\section{Los conglomerados y los espacios comunales/públicos}

Un segundo paso analítico ha supuesto considerar la existencia de al menos tres tipos de conglomerados: (1) conglomerados aislados de baja escala, los cuales comprometen un espacio mayor a modo de patio y otros menores a su alrededor; (2) conglomerados aislados de

Tabla 7. Guatacondo: distribución de formas de planta según rangos de tamaño. Table 7. Guatacondo: distribution of footprint shapes by size ranges.

\begin{tabular}{|c|c|c|c|c|c|c|c|c|c|c|c|c|c|c|}
\hline Guatacondo & $\begin{array}{c}0-5,1 \\
\mathrm{~m}^{2}\end{array}$ & $\%$ & $\begin{array}{c}5-10,1 \\
\mathrm{~m}^{2}\end{array}$ & $\%$ & $\begin{array}{c}10- \\
20,1 \\
\mathrm{~m}^{2}\end{array}$ & $\%$ & $\begin{array}{c}20- \\
40,1 \\
\mathrm{~m}^{2}\end{array}$ & $\%$ & $\begin{array}{c}40- \\
60,1 \\
\mathrm{~m}^{2}\end{array}$ & $\%$ & $\begin{array}{c}+60,1 \\
\mathrm{~m}^{2}\end{array}$ & $\%$ & Total & $\begin{array}{c}\text { Superficie } \\
\mathrm{m}^{2}\end{array}$ \\
\hline Rectangular & & & 1 & 1,85 & & & & & & & & & 1 & 5,21 \\
\hline Subrectangular & & & 6 & 11,11 & 2 & 3,51 & 1 & 3,85 & & & & & 9 & 103,51 \\
\hline Cuadrangular & & & & & 1 & 1,75 & & & & & & & 1 & 12,77 \\
\hline Subcuadrangular & 1 & 3,33 & 3 & 5,56 & 1 & 1,75 & 1 & 3,85 & & & & & 6 & 67,30 \\
\hline Circular & 1 & 3,33 & 6 & 11,11 & 9 & 15,79 & 1 & 3,85 & & & & & 17 & 194,45 \\
\hline Subcircular & 13 & 43,33 & 5 & 9,26 & 2 & 3,51 & & & & & & & 20 & 98,09 \\
\hline \multicolumn{15}{|l|}{ Elipsoidal } \\
\hline Oval & 3 & 10,00 & 4 & 7,41 & 8 & 14,04 & 5 & 19,23 & & & 1 & 33,33 & 21 & 2109,29 \\
\hline \multicolumn{15}{|l|}{ Trapezoidal } \\
\hline \multicolumn{15}{|l|}{ Triangular } \\
\hline Irregular & 12 & 40,00 & 29 & 53,70 & 34 & 59,65 & 18 & 69,23 & 3 & 100,00 & 2 & 66,67 & 98 & 1624,43 \\
\hline $\mathrm{n} / \mathrm{o}$ & & & & & & & & & & & & & 4 & \\
\hline Total & 30 & 100,00 & 54 & 100,00 & 57 & 100,00 & 26 & 100,00 & 3 & 100,00 & 3 & 100,00 & 177 & \\
\hline Superficie $\mathrm{m}^{2}$ & 93,13 & & 418,84 & & 771,21 & & 726,17 & & 130,87 & & 2074,81 & & & 4215,05 \\
\hline
\end{tabular}


Tabla 8. Caserones: distribución de formas de planta según rangos de tamaño. Table 8. Caserones: distribution of footprint shapes by size ranges.

\begin{tabular}{|c|c|c|c|c|c|c|c|c|c|c|c|c|c|c|}
\hline Caserones & $\begin{array}{c}0-5,1 \\
\mathrm{~m}^{2}\end{array}$ & $\%$ & $\begin{array}{c}5-10,1 \\
\mathrm{~m}^{2}\end{array}$ & $\%$ & $\begin{array}{c}10- \\
20,1 \\
\mathrm{~m}^{2}\end{array}$ & $\%$ & $\begin{array}{c}20- \\
40,1 \\
\mathrm{~m}^{2}\end{array}$ & $\%$ & $\begin{array}{c}40- \\
60,1 \\
\mathrm{~m}^{2}\end{array}$ & $\%$ & $\begin{array}{c}+60,1 \\
\mathrm{~m}^{2}\end{array}$ & $\%$ & Total & $\begin{array}{c}\text { Superficie } \\
\mathrm{m}^{2}\end{array}$ \\
\hline Rectangular & 77 & 48,13 & 91 & 64,54 & 95 & 66,90 & 50 & 53,19 & 29 & 53,70 & 33 & 71,74 & 379 & $11.205,70$ \\
\hline Subrectangular & 18 & 11,25 & 14 & 9,93 & 19 & 13,38 & 13 & 13,83 & 9 & 16,67 & 3 & 6,52 & 76 & 1458,80 \\
\hline Cuadrangular & 27 & 16,88 & 14 & 9,93 & 13 & 9,15 & 15 & 15,96 & 10 & 18,52 & 6 & 13,04 & 85 & 1746,40 \\
\hline Subcuadrangular & & & 3 & 2,13 & & & 1 & 1,06 & 1 & 1,85 & & & 5 & 80,80 \\
\hline Circular & 13 & 8,13 & 2 & 1,42 & 2 & 1,41 & 1 & 1,06 & 1 & 1,85 & 1 & 2,17 & 21 & 263,30 \\
\hline Subcircular & 7 & 4,38 & 2 & 1,42 & & & & & & & & & 9 & 27,88 \\
\hline \multicolumn{15}{|l|}{ Elipsoidal } \\
\hline Oval & 4 & 2,50 & 2 & 1,42 & 1 & 0,70 & 2 & 2,13 & & & & & 9 & 108,80 \\
\hline Trapezoidal & 2 & 1,25 & 1 & 0,71 & 1 & 0,70 & & & & & & & 4 & 29,20 \\
\hline Triangular & 2 & 1,25 & & & & & & & & & & & 2 & 8,90 \\
\hline Irregular & 10 & 6,25 & 11 & 7,80 & 11 & 7,75 & 12 & 12,77 & 4 & 7,41 & 3 & 6,52 & 53 & 1058,40 \\
\hline $\mathrm{n} / \mathrm{o}$ & & & 1 & 0,71 & & & & & & & & & 3 & 8,00 \\
\hline Total & 160 & 100,00 & 141 & 100,00 & 142 & 100,00 & 94 & 100,00 & 54 & 100,00 & 46 & 100,00 & 646 & \\
\hline Superficie $\mathrm{m}^{2}$ & 487,50 & & 1031,10 & & 2017,40 & & 2783,00 & & 2588,00 & & 7089,20 & & & $15.996,18$ \\
\hline
\end{tabular}

mayor envergadura y con mayor número de estructuras, siguiendo el patrón anterior, y (3) grandes agrupaciones de conglomerados formando barrios o sectores con numerosos recintos adicionados y contiguos de diversos tamaños, asociados a un lapso ocupacional más prolongado e intenso. Los tipos 1 y 2 involucran estructuras de planta elipsoidal, oval y circular en piedra y barro. El tipo 3 considera estructuras de muros curvos aunque mayormente con esquinas en ángulos rectos, vale decir, rectangulares y cuadrangulares.

Intentaremos, siguiendo este esquema, calificar algunas situaciones diagnósticas de integración y competencia en los aglomerados residenciales a nivel intrasitio e intersitio. Adicionalmente se considerará la ocurrencia de estructuras de mayor capacidad donde estimamos usos comunales o públicos, ya sea por varias unidades domésticas dentro de un asentamiento, o debido a una participación más extensa de agregados familiares o multifamiliares que habitaron sincrónicamente uno o varios asentamientos emparentados.

En Pircas, el cual hemos caracterizado como aquel sitio con un patrón arquitectónico disperso predominante y cuyas raíces tempranas son más evidentes (p. ej., uso de piedra, pilares verticales, muros curvados, unidades domésticas de planta elipsoidal y circular), presenta cinco conglomerados de estructuras con superficies construidas, que oscilan entre 124 y $1146 \mathrm{~m}^{2}$ (Tabla 9). Los de mayor tamaño se ubican en el sector nuclear estudiado por Núñez en 1984, aunque se distinguen otros hacia los extremos del asentamiento (SW y NE).

Lo importante en este caso es documentar la variación intrasitio según la inversión de trabajo (SC), diseño de planta entre estos conglomerados y respecto de la escala de aquellos más amplios donde se infieren distintos usos/ funciones (ceremoniales, funerarios, comunales, etc.). Por ejemplo, los espacios de gran tamaño se asocian a conglomerados cuyas dimensiones varían entre 65 y $970 \mathrm{~m}^{2}$, reforzando la idea de espacios multifamiliares comunes de distintas características (patios interiores o pequeñas plazas) (Tabla 10). Estos espacios de uso comunal identificados dentro de diversos conjuntos (p. ej., E.184, 198, 207, 240, 249 y 250) o como un negativo entre dos conglomerados (E.145), representan una superficie construida de $2058 \mathrm{~m}^{2}$, por lo tanto, ocupan cerca del $31,2 \%$ de la superficie construida en todo asentamiento que hemos registrado (Tablas 1 y 10).

En Pircas se observan tres variantes de conglomerados asociados con esta clase de espacios comunales o plazas. En primer lugar, en el conglomerado 1 se aprecian dos conjuntos alineados de pequeñas estructuras colindantes, los cuales dejan un patio interior de forma irregular (E.145: $970 \mathrm{~m}^{2}$ ), al modo de una plaza y pequeñas habitaciones y/o depósitos laterales. Luego, en los conglomerados en torno a pequeñas plazas o patios comunales (numerados como 249: $176 \mathrm{~m}^{2}$ y 184: $234 \mathrm{~m}^{2}$ ), usualmente de forma rectangular o irregular, 
Tabla 9. Superficie constructiva de los conglomerados domésticos. Table 9. Built area of domestic conglomerates.

\begin{tabular}{|c|c|c|c|}
\hline Sitio & Sector/Conglomerado & $\mathrm{N}^{\circ}$ estructuras (correlativo) & $\begin{array}{l}\text { Superficie constructiva } \\
\qquad\left(\mathrm{m}^{2}\right)\end{array}$ \\
\hline \multirow{3}{*}{ Ramaditas } & Conglomerado 1 & 1 a 5 & 950 \\
\hline & Conglomerado 2 & 18 a 32 & 315 \\
\hline & Conglomerado 3 & 40 a 60 & 850 \\
\hline \multirow{2}{*}{ Guatacondo } & Sector sur & 1 a 93 & 1382 \\
\hline & Sector norte & 94 a 173 & 995 \\
\hline \multirow{5}{*}{ Pircas } & Conglomerado 1 & 112 a 162 & 1146 \\
\hline & Conglomerado 2 & 185 a 209 & 440 \\
\hline & Conglomerado 3 & 238 a 240 & 124 \\
\hline & Conglomerado 4 & 250 a 252 & 614 \\
\hline & Conglomerado 5 & 247 a 249, 488 a 492 & 246 \\
\hline \multirow{7}{*}{ Caserones } & Sector noreste & 1 a 83 & 1250 \\
\hline & Sector sureste & 84 a 179 & 1682 \\
\hline & Sector centro-este & 180 a 239,254 a 267 & 972 \\
\hline & Sector centro & 270 a 351 & 1705 \\
\hline & Sector centro-oeste & 352 a 370,398 a 412,419 a 460,477 a 500 & 2245 \\
\hline & Sector centro-suroeste & 371 a 396,413 a 417,462 a 476,501 a 507 & 1562 \\
\hline & Sector oeste & 509 a 593 & 2079 \\
\hline
\end{tabular}

Tabla 10. Superficie constructiva y forma de espacios públicos. Table 10. Built area and shape of public spaces.

\begin{tabular}{|c|c|c|c|c|}
\hline Sitio & Plaza ( $\mathrm{N}^{\circ}$ estructura) & Superficie constructiva $\left(\mathrm{m}^{2}\right)$ & Forma de planta & Total edificado $\left(\mathrm{m}^{2}\right)$ \\
\hline \multirow{3}{*}{ Ramaditas } & 1 & 701 & Circular & \multirow{3}{*}{1148} \\
\hline & 24 & 148 & Elíptica & \\
\hline & 52 & 299 & Irregular & \\
\hline \multirow{3}{*}{ Guatacondo } & 10 & 123 & Irregular & \multirow{3}{*}{2075} \\
\hline & 45 & 114 & Irregular & \\
\hline & 174 & 1838 & Ovalada & \\
\hline \multirow{7}{*}{ Pircas } & 145 & 970 & Irregular & \multirow{7}{*}{2058} \\
\hline & 184 & 234 & Rectangular & \\
\hline & 198 & 65 & Irregular & \\
\hline & 207 & 79 & Rectangular & \\
\hline & 240 & 90 & Rectangular & \\
\hline & 249 & 176 & Cuadrada & \\
\hline & 250 & 444 & Irregular & \\
\hline \multirow{4}{*}{ Caserones } & 313 & 254 & Rectangular & \multirow{4}{*}{3415} \\
\hline & 314 & 229 & Rectangular & \\
\hline & 607 & 1482 & Rectangular & \\
\hline & 611 & 1450 & Rectangular & \\
\hline
\end{tabular}


se ejemplifica una modalidad también observada en Ramaditas, con un patio principal en torno al cual se adosan o agregan estructuras de menor tamaño interconectadas con la primera. Esta situación también se aprecia, como se verá más adelante, en el sector sur de Guatacondo. Una tercera modalidad la representa el conglomerado de $614 \mathrm{~m}^{2}$ en total, distribuido en torno a la estructura $\mathrm{N}^{\circ} 250\left(444 \mathrm{~m}^{2}\right)$, la cual constituiría una plaza subcircular delimitada por grandes bloques líticos colocados discontinuamente con un monolito al centro, junto al que se edificaría un pequeño conjunto de estructuras que totalizan $170 \mathrm{~m}^{2}$ intramuro. Esta modalidad recuerda directamente el formato de plaza ovalada con monolito central que en la aldea de Guatacondo alcanza características monumentales.

Ahora, observando el plano de Ramaditas, se definen tres conglomerados segmentados, los cuales siguen un patrón formalmente análogo a la segunda modalidad de Pircas. No obstante, en Ramaditas esta presenta una tecnología constructiva sumamente sofisticada en barro modelado y piedras seleccionadas por tamaño y color, cuyo aspecto final es de gran elaboración y durabilidad, con un trabajo cuidadoso para las fachadas exteriores, así como en el trabajo plástico, decorativo y ceremonial grabado en sus muros internos. El barro imprime una presencia más robusta y sólida de los edificios en un ámbito inclinado con amplia visibilidad hacia la pampa. De igual modo, el tamaño de los postes asociados al tamaño de las estructuras y su cobertura con techumbres extensas indican el despliegue de una amplia sombra artificial que ofrece una alternativa doméstica y cotidiana a aquella disponible en los bosques de Prosopis aledaños.

La oscilación en el tamaño de los conglomerados se registra entre 315 y $950 \mathrm{~m}^{2}$ (Tabla 9); una diferencia menos abrupta que aquellos conglomerados de Pircas. Más aun, cada conjunto cuenta con un espacio público o comunal propio que oscila entre 148 y $701 \mathrm{~m}^{2}$. Allí destaca la gran plaza con subdivisiones internas que presenta el conglomerado 1 (E-1 y E-5). Una evidente distinción entre Ramaditas y Pircas la vemos pues en la envergadura y el trabajo invertido en la edificación de los conglomerados residenciales (muros más anchos, más altos, con mayor diversidad de materiales, y elementos de ornamentación interna, etc.); suponemos resultado de una inspirada innovación que se fundamenta en el conocimiento acabado de las propiedades de las arcillas y los sedimentos en estado húmedo, como en un gesto conservacionista hacia los elementos de piedra y sus propiedades fundacionales, los cuales se mantienen en uso.

Según el estudio comparativo de Martindale (2005), el conglomerado 1 , en términos de la integración espacial y accesibilidad entre sus nodos, no sería tan distinto a los otros dos conjuntos o complejos; incluso podría constituir un espacio público compartido por los conglomerados 2 y 3. De acuerdo a lo anterior, vemos que los conglomerados 2 y 3 de Ramaditas se acercan a la segunda modalidad descrita para Pircas. En tanto el conglomerado 1 representaría un aumento notable en la superficie apta para ceremonias y la capacidad de audiencia máxima, singularizado por la complejidad interna (subdivisiones) del espacio respecto del resto de los sitios analizados. Los tres espacios comunales o públicos identificados (E-1, E-22 y E-54) ostentan una superficie constructiva acumulada de $1148 \mathrm{~m}^{2}$, lo cual indicaría que un porcentaje significativo de la inversión de trabajo $(48,5 \%)$ fue destinado a estos edificios (Tablas 1 y 10).

En tanto, la construcción de la aldea de Guatacondo resulta sumamente paradigmática al asemejarse al estilo constructivo de Ramaditas, manteniendo las fachadas interiores con pilares líticos fundacionales, adobones de distintas características, elementos modelados en sus muros interiores y la inclusión de hiladas de guijarros en aparejos sedimentarios. Además en ambos asentamientos predomina un patrón doméstico con viviendas circulares y ovales. Sin embargo, aquí el planeamiento aldeano ha alcanzado una alta densificación residencial (227 estructuras por ha) y la intensidad edificatoria revela que más de la mitad del perímetro ha sido aprovechado con construcciones que respetan el patrón formal o semblante del conjunto, sin irrupciones constructivas disonantes. Más bien, se constatan diferencias internas sectoriales (barrios) propias de estos nuevos espacios aldeanos (Tablas 9 y 10). En términos de inversión de trabajo, el sector sur posee una superficie construida mayor $\left(1382 \mathrm{~m}^{2}\right)$ que el sector norte $\left(995 \mathrm{~m}^{2}\right)$, situación que junto a una consideración diacrónica del crecimiento de los conjuntos, percibimos relacionada con la edificación de la plaza central (E.174) a partir de una estructura del sector sur (Meighan 1980). Esta diferenciación interna entre ambas mitades o barrios no sería relevante en términos constructivos según Meighan (1980); sin embargo, debemos agregar que la distinción sur-norte también se percibe en la ocurrencia de patios comunales solamente en el sector sur (E.10: $123 \mathrm{~m}^{2}$ y E.45: $114 \mathrm{~m}^{2}$ ). Esta última situación acerca esta clase de conglomerados a lo registrado en el conglomerado 2 de Ramaditas y en la modalidad 2 de Pircas (conglomerados 3 y 5) (Tabla 9).

A partir de la situación de Ramaditas, es evidente que el tamaño alcanzado por los conglomerados en la aldea de Guatacondo ha compelido a la comunidad a organizar sectorialmente sus barrios en torno a un gran espacio central, el cual representa probablemente una solución a las condiciones de alta densidad de habitantes 
presentes a partir del crecimiento de los conglomerados sureños. Aquí aparecen próximos, en términos de inversión de trabajo, el conglomerado 3 de Ramaditas $\left(850 \mathrm{~m}^{2}\right)$ y al sector norte de Guatacondo $\left(995 \mathrm{~m}^{2}\right)$ (Tabla 9), aunque la clase de asentamiento que integran es evidentemente distinta. En términos globales, las estructuras definidas como espacios comunales (E.10 y E.45) y públicos (E.174) presentan una superficie acumulada de $2075 \mathrm{~m}^{2}$, dentro de lo cual la plaza central representa el 88,6\%. Por lo tanto, el porcentaje edificado que presentan estos amplios edificios alcanza un 43,6\% del total construido respecto a los espacios intramuros de toda la aldea (Tablas 1 y 10).

Por último, en Caserones el crecimiento de los conglomerados residenciales alcanza un punto notable dentro de los cuatro sitios analizados. A pesar de ciertas diferencias -además de aquellas propiamente tecnológicas o constructivas-, que distinguen a Caserones de los sitios previamente descritos, sostendremos la ocurrencia de relaciones históricas perceptibles en el crecimiento diacrónico de sus barrios o sectores, al igual que lo referido en el caso de la aldea de Guatacondo. En primer lugar, en Caserones los barrios se perciben más ordenados o con una propuesta formal que les permite una expansión del espacio habitado más orgánica, eficiente y más práctica en cuanto a la inversión de trabajo realizada (McGuire \& Schiffer 1983). La zonificación que hemos realizado de los sectores (barrios) en Caserones (fig. 6) permite segregar siete conglomerados cuyas superficies constructivas oscilan entre 970 y $2245 \mathrm{~m}^{2}$ (Tabla 9). Esta variabilidad y segmentación debe tener necesariamente una lectura diacrónica, aunque también debe percibirse como la presión y el interés por habitar densamente el asentamiento (densidad: 172 estructuras por ha) en desmedro de sectores vacíos fuera de su perímetro. El uso intenso del suelo interno del asentamiento para las construcciones (FOS: 42,65\%) se acerca porcentualmente en este plano a la aldea de Guatacondo (Tabla 1).

Destacan entre los agregados sectoriales aquellos definidos como este-norte y este-sur, los cuales se asemejan espacialmente a la modalidad 1 descrita en Pircas, esto es, dos conglomerados que dejan un patio negativo interior entre ellos o análogamente, aunque a otra escala, lo que ocurre con la distribución bipartita norte y sur de Guatacondo en torno a un espacio central. A diferencia de lo que plantea Núñez (2006), esto hace pensar que el sector este ( $\mathrm{N}$ y $\mathrm{S}$ ) se relaciona con un planeamiento aldeano compartido -probablemente más temprano que el resto del asentamiento (macrosectores central y oeste)-, puesto que comparte características identificadas en Pircas y Guatacondo, tanto en la distribución como en el crecimiento de estos barrios en particular.
Los espacios públicos rectangulares (E.313-314 y E.607-611), en tanto, aparecen como conjuntos dobles de plazas laterales al eje NE-SW del asentamiento. La primera, en el centro norte, representa un espacio techado posiblemente reconstruido en las diversas fases ocupacionales del asentamiento (True 1980). Discrepamos con Núñez (1984 y 2006) sobre que este conjunto correspondería a edificios inkaicos o históricos, debido a que los desechos recuperados en excavación como la mampostería y circulación se correlacionan con el resto de la aldea (Vidal 2012). Dos elementos notables de estos patios ceremoniales "gemelos" en gran parte techados, es su acceso restringido y lineal desde la estructura 313 $\left(254 \mathrm{~m}^{2}\right)$, como antesala a la estructura $314\left(229 \mathrm{~m}^{2}\right) \mathrm{y}$, en segundo lugar, el tratamiento con un revestimiento exterior de ambas estructuras, con pequeños bolones de anhidrita de menos de $10 \mathrm{~cm}$ de diámetro (huevillos), que le otorgan un aspecto notablemente más cuidado que el resto de la aldea. En el lado opuesto de la aldea, hacia el sur, se registran dos plazas abiertas de gran tamaño, las cuales además se encuentran vinculadas, mediante el apoyo y la traba de muros, a la construcción del cierre perimetral de la aldea. Ambas (E-607: 1482 m² $^{2}$ y E-611: $1450 \mathrm{~m}^{2}$ ) unidades presentan cualidades de diseño replicativas y constructivas similares (Tabla 10). En superficie, la primera (poniente) se registra sumamente limpia o despejada de desechos, en tanto la segunda (oriente) cubierta con basurales monticulares. Esta plaza abierta oriental presenta varias estructuras rectangulares adosadas a su interior, las cuales han sido construidas a partir del muro divisorio con plaza poniente (E.607).

No sabemos si estas plazas funcionaron de forma paralela (una limpia y otra como receptora de las basuras) o la segunda (E.611) fue la plaza abierta más antigua, siendo abandonada al momento de la instalación de una nueva (E.607). Debido a que incluimos en nuestra evaluación tanto los dos recintos techados del sector centro-norte, como aquellos dos patios o plazas abiertas del centro-sur, los espacios públicos definidos acumulan una superficie constructiva de $3415 \mathrm{~m}^{2}$, es decir un $21,4 \%$ de la superficie total del asentamiento (Tablas 1 y 10), mucho menor proporcionalmente al resto de los sitios analizados.

Recapitulando, los cuatro asentamientos que hemos caracterizado demuestran un crecimiento singular y a la vez constante de los conglomerados residenciales (Tabla 9), los cuales estimamos se ordenan diacrónicamente desde Pircas, pasando por Ramaditas y Guatacondo hasta Caserones. Vemos, en este sentido, un notable crecimiento y perdurabilidad de modalidades arquitectónicas practicadas en los espacios residenciales, especialmente en Pircas, Ramaditas y Guatacondo. 
Allí, en Pircas y Ramaditas, los conglomerados estarían vinculados a sus propios espacios comunales o públicos en modalidades diversas dentro de cada asentamiento, mientras que en la quebrada de Guatacondo sus habitantes innovarían mediante un pacto de fusión política, creando un verdadero espacio aldeano integrado. Es en estas circunstancias que el espacio público o la plaza de Guatacondo resulta ser un cohesionador del conjunto, adquiriendo características formales centralizadoras, al modo de una gran vivienda colectiva para la comunidad que en torno a ella habita y que en cierto modo ha destinado concertadamente una fuerza de trabajo mayor proporcionalmente a la inversión en espacios domésticos que se han construido previamente a su alrededor. Visto en una línea de cambio decreciente, en Ramaditas el 48,45\% de la superficie del asentamiento está destinado a espacios comunales o públicos, mientras en Caserones ese porcentaje se reduce a $21,35 \%$ de la superficie del asentamiento (Tabla 1); tendencia a la cual se contrapone aquella ascendente que manifiesta el crecimiento, la inversión de trabajo y las modalidades de conglomerados, sectores y barrios residenciales en los cuatro sitios estudiados (Tabla 10).

\section{Elementos de diseño arquitectónico y fisonomía de la traza resultante}

La información relevada en términos morfofuncionales y tecnológicos -aquella relativa a los tipos de unidades domésticas, conglomerados y espacios públicos existentes en los cuatro asentamientos analizados y sus relaciones-, nos permite establecer relaciones y distinciones de acuerdo a nuestra consideración inicial acerca de las tradiciones y los ámbitos de desarrollo de los asentamientos formativos en el área (Duke 1996; Urbina et al. 2011).

Debido a la envergadura de los sitios, hemos privilegiado una mirada macro sobre ciertos elementos del diseño arquitectónico, como las formas de planta, los tamaños y los índices constructivos (Tablas 1, 2, 3 y 4). Por otra parte, vemos concatenados ciertos elementos constructivos en la serie Pircas-Ramaditas-GuatacondoCaserones, establecida con fines analíticos. En los tres primeros sitios se mantienen rasgos tempranos, como la socavación del terreno seleccionado para los edificios, el uso de pilares fundacionales y muros curvos; mientras que entre Pircas y aquellos de la quebrada de Guatacondo se observa una evidente distancia relacionada con el uso versátil del barro, elementos ornamentales como modelados al interior de viviendas y espacios públicos. En cuanto a la orgánica de los asentamientos existe un tránsito de conglomerados segmentados hacia asentamientos de carácter aldeano con barrios residenciales de mayor envergadura centralizados por arquitectura pública, cuyo ejemplo es Guatacondo. En los cuatro sitios se observa un uso sostenido de la infraestructura de almacenaje mediante pozos cavados en el sustrato interior de las viviendas o los patios a modo de bodegas o silos, aunque sus usos y volúmenes proporcionales de almacenaje pudieron variar entre unos y otros. El tamaño de los sectores norte y sur de Guatacondo tiene más que ver con aquellos sectores más pequeños de Caserones (E-S y E-N), que con aquellos conglomerados de Pircas.

En términos cuantitativos, hemos agrupado familias de formas según la presencia de muros curvos (circulares, subcirculares, ovoidales, elipsoidales) y muros con ángulos (cuadrangulares, rectangulares y sus derivadas), así como plantas no determinables en la familia irregular que incluyen formas no adscribibles a las anteriores. De este modo, según lo indica el Gráfico 1, Pircas y Ramaditas se encontrarían claramente emparentados según el diseño resumido de sus formas de planta, de hecho la familia circular supera en ambos el 60\%, mientras la familia cuadrangular alcanza un 8,2\% en Pircas y un 3,6\% en Ramaditas. La aldea de Guatacondo señalaría una ruptura relativa con ambos asentamientos, en tanto la tendencia correspondería a las plantas de forma irregular $(55,4 \%)$, seguramente por el estado de conservación del sitio, pero también por el alto índice de aglutinamiento o proximidad de las estructuras. De hecho, Meighan (1980) destaca que ciertas estructuras han sido concebidas edificando varios segmentos de muros. A pesar de lo anterior, la disposición de diseño principal continúa siendo la familia circular con un 32,8\%, mientras la familia cuadrangular asciende hasta casi un $10 \%$. Caserones, por su parte, modifica radicalmente el patrón de Guatacondo, con una familia cuadrangular cuya representación es significativa $(84,3 \%)$, mientras de lejos se perciben las influencias y la utilidad de los espacios de muros curvos (6\%); inclusive este tipo de diseño de planta es capaz de minimizar la presencia de estructuras de formato irregular por debajo del 10\%.

Respecto de los tamaños, el Gráfico 2 señala las curvas descritas por las frecuencias relativas que ostentan los rangos de tamaño en cada sitio dentro. La lectura de este gráfico refuerza ciertas pautas funcionales y distinciones intersitios anteriormente enunciadas. En primer lugar, aparece nuevamente Pircas con una trayectoria que señala la ocurrencia mayoritaria de pequeñas estructuras, aisladas o integrando conglomerados dentro de su extensa superficie. Es posible que la presencia de ocupaciones arcaicas, como también posteriores formativas, en forma de paraderos, parapetos o refugios, estén incidiendo en 


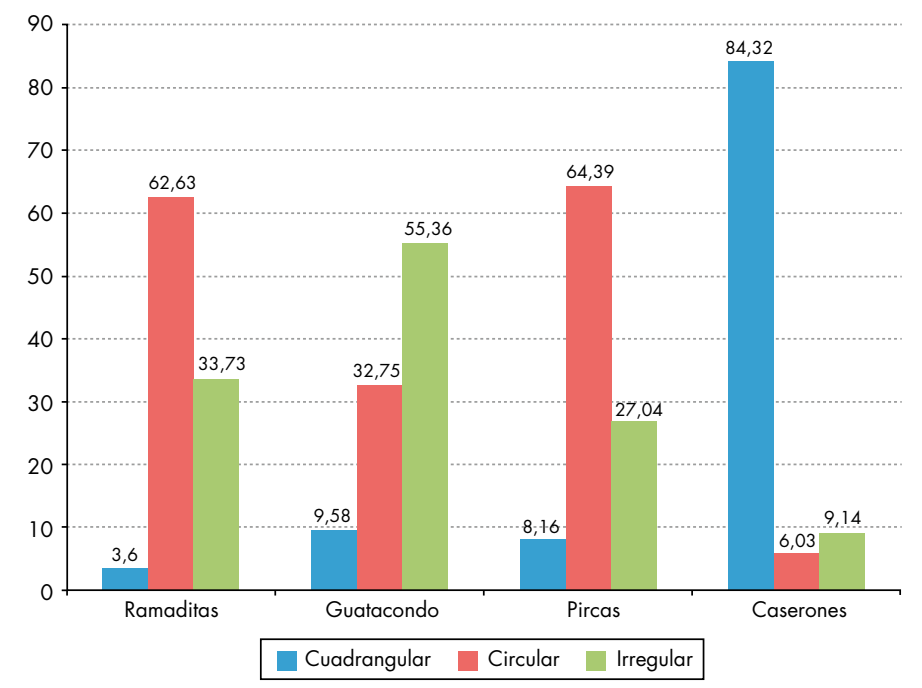

Gráfico 1. Distribución porcentual patrones de planta por sitio.

Graph 1. Percentage distribution of floor plan patterns by site.

una sobrerrepresentación del primer rango de tamaño. Luego se observa una capacidad habitacional deprimida respecto a los tres sitios restantes. De igual modo que en la presencia de espacios de gran tamaño, Pircas se acerca a la situación de Guatacondo en el quinto y sexto rango de tamaño.

Las curvas de Ramaditas y Guatacondo son similares, especialmente en la proporción de espacios de almacenaje y capacidad habitacional, aunque el primer asentamiento se distingue de la aldea en una mayor presencia de estructuras mayores a $40,1 \mathrm{~m}^{2}$ que corresponden a patios o plazas. Ambos sitios, sin duda, forman parte de una misma tradición arquitectónica, con distintas expresiones funcionales o sociales, las cuales pudieron ser contemporáneas y a la vez manifestar cierta transformación, desde Ramaditas a Guatacondo, en la estructura de los grupos sociales de la quebrada. Esta transformación, que hemos enunciado, ocurre desde conglomerados residenciales más pequeños pero con mayor inversión en espacios comunales o públicos, hasta asentamientos o sectores residenciales de mayor envergadura con espacios públicos comunes a todos ellos. La curva de Caserones señala una funcionalidad notable del asentamiento dedicada al almacenaje, casi a la par con los espacios habitacionales. El descenso en los últimos tres rangos de tamaño $\left(20,1 \mathrm{~m}^{2}\right.$ hasta mayores de $60 \mathrm{~m}^{2}$ ) es un rasgo común en los cuatro asentamientos, aunque en Caserones sería de mayor

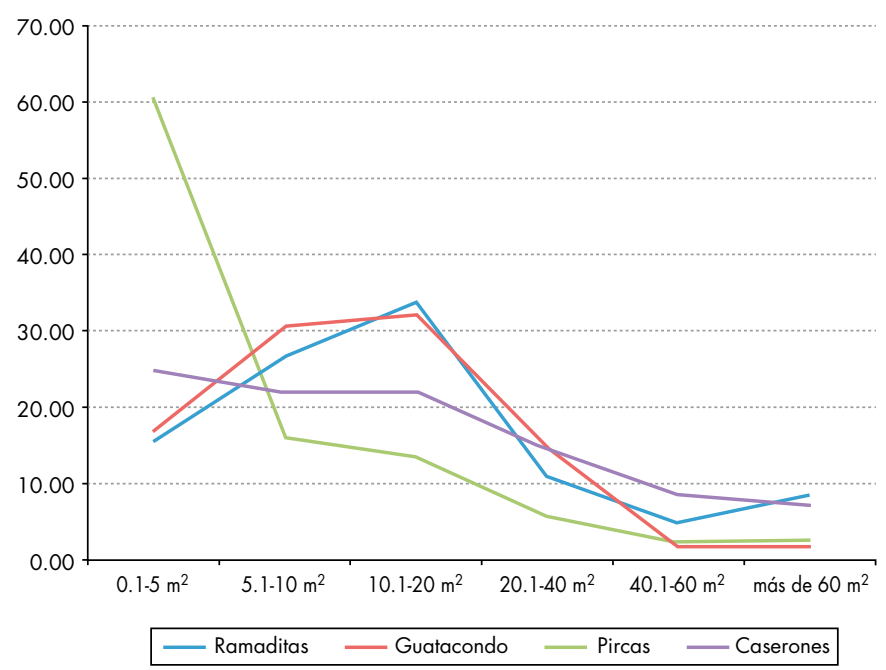

Gráfico 2. Curvas rangos de tamaño por sitio.

Graph 2. Curves showing size ranges for each site. 
significación ya que refiere en estas circunstancias a la presencia de espacios a modo de patios, corrales y plazas públicas como parte inherente al diseño de los distintos sectores o barrios del sitio.

\section{RECAPITULACIÓN}

Considerando la calibración de los fechados por radiocarbono obtenidos por nuestro proyecto (Tabla 11), los lapsos ocupacionales de los sitios analizados plantearían grados de sincronía y longevidades distintas para los modos constructivos referidos anteriormente. En primer lugar, considerando que hasta la fecha la quebrada de Tarapacá es la única que presenta antecedentes Arcaicos datados en 6000 AC (Núñez 1979), disponemos de mayores argumentos para comprender la continuidad de dicha ocupación en los conglomerados de Pircas entre el siglo VII AC (Meighan \& True 1980; Tartaglia 1980) y hasta el siglo vi DC (Tabla 11). Además, Pircas presenta un lapso ocupacional sincrónico con Caserones, este último estimado entre el siglo vi AC (Meighan \& True 1980; Tartaglia 1980) y el xI DC (Tabla 11), siendo ambos contemporáneos entre los siglos vi AC y vi DC. Aquí las diferencias entre Pircas y Caserones recaen más en las tecnologías constructivas, la densificación, el tipo de agregación y los tipos de conglomerados y sectores, así como las relaciones establecidas tempranamente (siglos Iv AC-I DC) con otros asentamientos como Ramaditas y Guatacondo (Tabla 11).

A pesar de lo anterior, ambas tradiciones arquitectónicas serían parte del Período Formativo con elementos iniciales, remanentes o más conservadores en Pircas (tradición temprana en piedra), y más tardíos e innovadores, respecto de la respuesta o diseño que exhibe Caserones frente a su vecino en la quebrada. Esta coexistencia repercutirá sin duda en las relaciones que se establezcan con la costa o las competencias que establecieron entre dichos agrupamientos de personas, familias, linajes, lo cual parece evidente en la ubicación de sus cementerios (Tr-40 y Pircas 2 y 6) (Núñez 2006; Núñez y Santoro 2011), y que interpretamos como cierta pugna, "manteniendo las distancias", por el lecho de la quebrada de Tarapacá.

Internamente en Pircas, la secuencia ocupacional estaría determinada por la aparición de nuevos conglomerados por fisión y segmentación, los cuales no se aglutinan sobre los $614 \mathrm{~m}^{2}$, o por la reutilización del asentamiento mediante estructuras dispersas en torno al núcleo central. En Caserones (siglos VI AC y xI DC), en cambio, la secuencia constructiva se iniciaría en el sector este, pero continuaría de forma abigarrada, y competitiva, hacia el oeste del asentamiento, mediante al menos cinco nuevos conglomerados que se acomodaron sin una planificación rígida a un ordenamiento aldeano paralelo a la quebrada (figs. 5a y 6). Los cuatro conglomerados centrales definen, en cierta manera, la ocurrencia de arquitectura pública al norte (E.313-314 y E.607-611), a la vez que las plazas abiertas al sur se relacionan constructivamente con la edificación del muro perimetral (fig. 5b). Por esta razón, es posible plantear que los sectores centro-oeste y oeste habrían sido los últimos en ser edificados, respetando los límites impuestos por el cierre perimetral y la plaza abierta más occidental. La clausura del asentamiento mediante su muro perimetral doble, señala un momento político y territorial álgido, situado hacia el siglo vi DC (True 1980).

En la quebrada de Guatacondo, Ramaditas exhibe un lapso ocupacional entre el siglo IX AC (Rivera 2005) y I DC (Tabla 11), algo más temprano que el de Guatacondo, entre el VII AC (Meighan \& True 1980; Tartaglia 1980) y el siglo i DC (Tabla 11), no obstante, en el cementerio (G-12) aledaño a la aldea de Guatacondo existe una fecha calibrada con un lapso aún más temprano entre los años 1129 y 843 AC (Meighan \& True 1980). En este sentido, ambos asentamientos muestran atributos de contemporaneidad y probablemente de complementariedad funcional asociadas a la ocupación de la quebrada antes de su desecamiento y abandono (siglo i DC?); la organización de sus habitantes debió ocurrir habitando ambas clases de sitios. En efecto, se debe recalcar la existencia de dos modalidades de organización de los espacios domésticos entre ambos asentamientos, segmentado en Ramaditas y aglutinado, pero conservando una diferenciación sectorial o barrial en Guatacondo, aunque en este último, la presencia de arquitectura pública imprime un sello distintivo y aglutinante en el conjunto aldeano a una escala no registrada con anterioridad en la historia tarapaqueña.

Entre las quebradas analizadas, vemos que la mayor correlación cronológica en los lapsos ocupacionales se registra entre la aldea de Guatacondo y Caserones (entre los siglos VI AC y i DC). Por otra parte, existirían además elementos más específicos, que acercarían funcional y temporalmente a los cuatro asentamientos, por ejemplo, la ocurrencia de la modalidad 1 de conglomerados de Pircas, los cuales dejan un patio o explazo interior, el que se aprecia también en los sectores este-norte y estesur de Caserones, así como en los sectores norte y sur de Guatacondo. Esta organización pudo comprometer una diferenciación social en mitades o parcialidades según plantea Meighan (1980). La modalidad 2 de Pircas aludiría al formato de los conglomerados de Ramaditas, con un espacio comunal o público, en torno al que se 
Tabla 11. Fechados radiocarbónicos de los sitios analizados (Proyecto FONDECYT 1080458). Table 11. Radiocarbon datings of the sites analyzed (FONDECYT Project 1080458).

\begin{tabular}{|c|c|c|c|c|c|}
\hline Código & Sitio & Recinto & Nivel & Muestra & Rango de edad calendárica $\left(P \_0,95\right)$ \\
\hline \multirow[t]{2}{*}{ Beta-314509 } & Ramaditas & 17 & Superficie & Madera & 390-340 cal. AC \\
\hline & Ramaditas & & & & 320-200 cal. AC \\
\hline \multirow[t]{2}{*}{ Beta-314510 } & Ramaditas & 41 & 4 & Madera & $390-340 \mathrm{cal} . \mathrm{AC}$ \\
\hline & Ramaditas & & & & 320-200 cal. AC \\
\hline \multirow[t]{3}{*}{ Beta-314512 } & Ramaditas & 9 & 3/Rasgo 1 & Carbón & 350-320 cal. AC \\
\hline & Ramaditas & & & & 210-90 cal. AC \\
\hline & Ramaditas & & & & 80-50 cal. AC \\
\hline \multirow[t]{2}{*}{ Beta-314511 } & Ramaditas & 41 & 1 & Carbón & $110 \mathrm{cal} . \mathrm{AC}-30 \mathrm{cal} . \mathrm{AC}$ \\
\hline & Ramaditas & & & & 40-50 cal. DC \\
\hline Beta-314508 & Ramaditas & 51 exterior & $1 /$ Rasgo 1 & Carbón & 40-80 cal. DC \\
\hline \multirow{2}{*}{ Beta-294697 } & Guatacondo & 153 & 7 & Carbón & 340-330 cal. AC \\
\hline & Guatacondo & & & & 200 cal. AC-20 cal. DC \\
\hline \multirow[t]{2}{*}{ Beta-294696 } & Guatacondo & 99 & Rasgo 1 & Carbón & 200-10 cal. AC \\
\hline & Guatacondo & & & & $160-130 \mathrm{cal} . \mathrm{AC}$ \\
\hline \multirow[t]{2}{*}{ Beta-314501 } & Guatacondo & 3 & 5 & Vegetal & 120 cal. AC-10 cal. DC \\
\hline & Guatacondo & & & & 10-20 cal. DC \\
\hline \multirow[t]{2}{*}{ Beta-294698 } & Guatacondo & 164 & 4 & Carbón & 160 cal. AC-60 cal. DC \\
\hline & Guatacondo & & & & 90-80 cal. AC \\
\hline Beta-314500 & Guatacondo & 153 & 7 & Vegetal & $50 \mathrm{cal}$. AC-60 cal. DC \\
\hline Beta-314502 & Guatacondo & 3 & 4 & Carbón & $50 \mathrm{cal} . \mathrm{AC}-70 \mathrm{cal} . \mathrm{DC}$ \\
\hline \multirow[t]{2}{*}{ Beta-294700 } & Guatacondo & 232 & 3 & Carbón & 370-150 cal. AC \\
\hline & Guatacondo & & & & 140-110 cal. AC \\
\hline \multirow[t]{2}{*}{ Beta-294701 } & Pircas & 251 & $3 \mathrm{~B}$ & Carbón & 80-230 cal. DC \\
\hline & Pircas & & & & $350-440$ cal. DC \\
\hline \multirow[t]{2}{*}{ Beta-294699 } & Pircas & 198 & Rasgo 2 & Madera & 490-520 cal. DC \\
\hline & Pircas & & & & $380-450$ cal. DC \\
\hline \multirow[t]{2}{*}{ Beta-294702 } & Pircas & 269 & $3 \mathrm{~B}$ & Madera & 450-460 cal. DC \\
\hline & Pircas & & & & 480-530 cal. DC \\
\hline Beta-294695 & Caserones & 61 & 7 & Carbón & 20-240 cal. DC \\
\hline Beta-220919 & Caserones & 526 & $5 \mathrm{C}$ & Carbón & $80-250$ cal. DC \\
\hline Beta-220918 & Caserones & 468 & $3 \mathrm{~A}$ & Madera & $110-410$ cal. DC \\
\hline Beta-294694 & Caserones & 433 & $2 \mathrm{~A}$ & Carbón & 250-420 cal. DC \\
\hline Beta-220917 & Caserones & 7 & 3 & Carbón & 890-1020 cal. DC \\
\hline
\end{tabular}

Nota: Fechados calibrados a dos sigmas con el programa INTCAL 04 e INTCAL 09 (Oeschger et al. 1975; Stuiver \& Braziunas 1993; Heaton et al. 2009; Reimer et al. 2009).

Fuente: Uribe \& Vidal 2012, Tabla 2: 232. 
agregan celularmente otros de menor tamaño (Adán et al. 2010), el cual se emparentaría con el típico patrón de Tierras Altas identificado en la subárea Circumpuneña (Adán \& Urbina 2007). Este sería apreciable de igual modo en los sectores NW y SE de Guatacondo (Mostny 1970; Meighan 1980) donde se plantea el crecimiento progresivo de los conglomerados a partir de estructuras primarias. Por último, el conglomerado en la modalidad 3 de Pircas establece una sugerente conexión entre ambas quebradas, mediante el uso de espacios circulares despejados con un monolito al centro (Núñez 1984: 154, 172, fig. 5b), análogo a lo descrito en la plaza central de Guatacondo, la cual podría ser previa al siglo I DC.

\section{PALABRAS FINALES}

Hemos considerado necesario documentar distintos patrones residenciales aglutinados que permitan comprender la singularidad y la relación arquitectónica de asentamientos ubicados en el sector más desértico de los Valles Occidentales. Aunque poco se ha tratado la inserción y el manejo de estos espacios en relación con sus potencialidades agrícolas, forestales y silvícolas -provistos además con importantes recursos hídricos, vegetacionales y faunísticos en torno a la pampa del Tamarugal-, debido a su localización es evidente la valoración que tales poblaciones han hecho de ambas quebradas, no solo en términos habitacionales, sino también en una fuerte expresión simbólica asociada a situaciones de identidad territorial y étnica durante esta época (Núñez 1984: 165-166).

Es por ello que a partir de expresiones iniciales y que contienen mayor variabilidad, las tradiciones arquitectónicas de Tarapacá son objeto de notables transformaciones sociales. El caso de Caserones representaría un momento culminante referido al crecimiento demográfico y la complejidad política ostentada por sus residentes y autoridades (siglos VI y XI DC), pero también situaciones de innovación, competencia y readecuación histórica las cuales permitieron soluciones aparentemente distintas o casi imposibles de comparar con otros asentamientos contemporáneos y vecinos (Núñez 1984). En este sentido, nuestro argumento -basado en una mirada intrarregional- ha identificado un conjunto de elementos constructivos, de diseño, rasgos conspicuos o únicos, los que a su vez relacionan cada asentamiento y sus poblaciones no solo considerándolos como una comunidad cerrada en sí misma, sino vinculándolas al espacio y el tiempo histórico en los que se han desarrollado fuertemente "modos de habitar" y ocupar el ámbito de tierras bajas interiores, las quebradas bajas endorreicas y la pampa. Visto de otro modo, estos asentamientos junto a aquellos de la costa desértica y las quebradas altas adyacentes, integran y configuran desde este período la región formativa de Tarapacá.

RECONOCIMIENTOS A los equipos integrantes de los proyectos FONDECYT 1030923 y 1080458 , especialmente a Mauricio Uribe, Carolina Agüero y Antonio Maldonado. A Andrés Velásquez y Roberto Izaurieta por los levantamientos topográficos. A todos los que realizaron el lento fichaje de arquitectura en las campañas de 2005 y 2009.

\section{NOTAS}

${ }^{1}$ El estudio consideró la aplicación de la ficha de registro arquitectónico propuesta para el Pukara de Turi por Castro y colaboradores (1993: 86-87, Anexo 2: 103-105) con modificaciones. La aplicación de esta ficha de registro, junto con la utilización de instrumentos de medición (GPS-Datum WGS ‘84, brújula y huincha métrica), permitió relevar la totalidad de las estructuras de los sitios seleccionados (100\%). Cada ficha arquitectónica consigna la siguiente información: 1) Croquis: sin escala y a mano alzada; 2) Planta: forma, dimensiones y superficie (medidas en metros); 3) Paramentos: hilada, aparejo, aplomo, materiales; 4) Vanos: puertas, acceso, ventanas; 5) Estructuras y elementos complementarios, y 6) Observaciones generales (materiales en superficie, rasgos, etc.). Finalmente se realizó el levantamiento topográfico de los asentamientos.

2 Para la comparación de los asentamientos, fue tabulada la información de estos atributos de acuerdo al enfoque regional definido por Willey (1968: 217) según el cual "[...] la data del asentamiento se integra sincrónicamente mediante el estudio y la demostración de la relación entre ciudades, pueblos y estancias del patrón zonal". La presente investigación se apoya en una estrategia metodológica cuya unidad de análisis histórica y sociológica es el asentamiento (Chang 1976). Su objetivo primario, basado en el registro de arquitectura y áreas de actividad, es el análisis intra e intersitios para realizar inferencias sobre la organización social de las culturas y sus relaciones sociales "utilizando datos arqueológicos [...] y la investigación de los aspectos sincrónicos o estructurales y diacrónicos o del desarrollo de esas relaciones" (Trigger 1967: 151). Las traducciones del inglés son nuestras.

\section{REFERENCIAS}

ADÁN, L., 1999. Aquellos antiguos edificios. Un acercamiento arqueológico a la arquitectura prehispánica tardía de Caspana. Estudios Atacameños 18: 13-34.

AdÁn, L. \& S. UnBina, 2007. Arquitectura Formativa en San Pedro de Atacama. Estudios Atacameños 34: 7-30.

— 2008. Historia arquitectónica de la localidad de Pisagua (I Región, Chile): Una tradición olvidada en los períodos tardíos del área Pica-Tarapacá. En Problemáticas de la arqueología contemporánea, A. Austral \& M. Tamagnini, Eds., vol. 2, pp. 723-734, Universidad Nacional de Río Cuarto.

— 2010. Arquitectura quebradeña del Complejo Pica Tarapacá: Modos de hacer, opciones de diseño, rasgos significativos, decisiones funcionales. En Actas del XVII Congreso Nacional de Arqueología Chilena, pp. 865-876. Valdivia: Sociedad Chilena de Arqueología, Dirección Museológica, Universidad Austral de Chile.

ADÁN, L.; M. UriBE \& S. UrBinA, 2007. Arquitectura pública y doméstica en las quebradas de Tarapacá: Asentamiento y dinámica social 
en el Norte Grande de Chile. En La vivienda, la comunidady el territorio, A. Nielsen, C. Rivolta, P. Mercolli, M. Vásquez \& V. Seldes, Eds., pp. 183-206. Córdoba: Editorial Brujas.

Aldunate, C.; J. Berenguer, V. Castro, L. Cornejo, J. L. Martínez \& C. Sinclaire, 1986. Cronología y asentamiento en el Región del Loa Superior. Dirección de Investigación y Bibliotecas de la Universidad de Chile, Santiago.

Ayala, P., 2001. Las sociedades formativas del Altiplano Circuntiticaca y Meridional y su relación con el Norte Grande de Chile. Estudios Atacameños 21: 7-39.

Blanton, R.; G. Feinman, S. Kowalewsisi \& P. Peregrine, 1996. A dualprocessual theory for the evolution of Mesoamerican civilization. Current Anthropology 37 (1): 1-14, Chicago.

Bordieu, P., 1977. Outline of a Theory of Practice. Cambridge: Cambridge University Press.

Briones, L.; L. NúÑez \& V. Standen, 2005. Geoglifos y tráfico prehispánico de caravanas de llamas en el desierto de Atacama (norte de Chile). Chungara 37 (2): 195-223.

BRUYNE, E. DE., 1963. Informe sobre el descubrimiento de un área arqueológica. En Publicación ocasional del Museo Nacional de Historia Natural 2: 1-16, Santiago.

CAstro, V.; F. Maldonado \& M. VÁsquez, 1993. Arquitectura del pukará de Turi. En Actas del XII Congreso Nacional de Arqueología Chilena, pp.79-106. Temuco: Sociedad Chilena de Arqueología, Dirección de Bibliotecas, Archivos y Museos, Museo Regional de la Araucanía.

Chang, K., 1968. Settlement archaeology. Palo Alto, California: National Press Book.

— 1976. Nuevas perspectivas en arqueología. Madrid: Alianza Editorial.

Cornejo, L., 2007. Contando y pesando: Un ensayo sobre las bases para el razonamiento cuantitativo contemporáneo en arqueología. Boletín de la Sociedad Chilena de Arqueología 40: 7-14, Santiago.

DukE, P., 1996. Braudel and North American Archaeology: An example from the Northern Plains. En Contemporary Archaeology in theory, R. W. Preucel \& I. Hodder, Eds., pp. 240-257. Oxford: Blackwell Publishers.

Graffam, G.; M. Rivera \& A. Carevic, 1996. Ancient Metallurgy in the Atacama: Evidence for Copper Smelting during Chile's Early Ceramic Period. Latin American Antiquity 7: 101-113, Washington D. C.

Heaton, T. J.; P. G. Blackwell \& C. E. Buck, 2009. A Bayesian approach to the estimation of radiocarbon calibration curves: The IntCal09 methodology. Radiocarbon 51, 1151-1164, Arizona.

HodDer, I., 1990. Textos de cultura material y cambio social: Una discusión teórica y algunos ejemplos arqueológicos. Boletín de Antropología Americana 21: 24-39, México, D. F.

Lumbreras, L., 2006. Un Formativo sin cerámica y cerámica preformativa. Estudios Atacameños 32: 11-34.

MARTINDALE, A., 2005. A Method for Analyzing Vernacular Architecture: A Case Study from the Ramaditas Site, Chile. En Arqueología del desierto de Atacama: La etapa formativa en el área de Ramaditas/Guatacondo, M. Rivera, Ed., pp. 133-173. Santiago: Editorial Universidad Bolivariana Colección Estudios Regionales y Locales.

MCGUiRe, R. \& M. SCHIFFER, 1983. A theory of architectural design. Journal of anthropological archaeology 2: 227-303.

Meighan, C., 1980. Archaeology of Guatacondo, Chile. En Prehistoric trails of Atacama: Archaeology of Northern Chile, Monumenta Archaeologica 7, C. W. Meighan \& D. L. True, Eds., pp. 99-126. Los Angeles: The Institute of Archaeology, University of California.

Meighan, C \& D. True, 1980. Prehistoric trails of Atacama: Archaeology of northern Chile. Monumenta archaeologica 7. Los Angeles: The Institute of Archaeology, University of California.

Moore, J., 1996. Architecture and power in the Ancient Andes: The Archaeology of Public Buildings. Cambridge: Cambridge University Press.
Mostny, G., 1970. La subárea arqueológica de Guatacondo. Boletín del Museo Nacional de Historia Natural 16: 271-289, Santiago.

- 1980. The archaeological zone of Guatacondo. En Prehistoric trails of Atacama, C. Meighan \& D. True, Eds., pp. 91-97. Monumenta Archaeologica 7, University of California, Los Angeles.

Nielsen, A., 1995. Architectural performance and the reproduction of social power. En Expanding Archaeology, J. Skibo, W. Walker \& A. E. Nielsen, Eds., pp 47-66. Salt Lake City: University of Utah Press.

Niemeyer, H., 1989. El escenario geográfico. En Prehistoria de Chile. Desde sus orígenes hasta los albores de la Conquista, Hidalgo, J., V. Schiappacasse, H. Niemeyer, C. Aldunate \& I. Solimano, Eds., pp. 1-12. Santiago: Editorial Andrés Bello.

Niemeyer, H. \& M. Rivera, 1983. El Camino del Inka en el Despoblado de Atacama. Boletín de Prehistoria de Chile 9: 91-193, Santiago.

NúÑEz, L., 1966. Caserones-I, una aldea prehispánica del Norte de Chile. Estudios arqueológicos 2: 25-29, Antofagasta.

— 1979. Emergencia y desintegración de la sociedad tarapaqueña: Riqueza y pobreza de una quebrada del norte chileno. Atenea 439: 163-213, Concepción.

— 1982. Temprana emergencia del sedentarismo en el desierto chileno. Proyecto Caserones. Chungara 9: 80-122.

— 1984. El asentamiento Pircas: Nuevas evidencias de tempranas ocupaciones agrarias en el norte de Chile. Estudios Atacameños 7: 152-167.

— 1989. Hacia la producción de alimentos y la vida sedentaria (5000 AC-900 DC). En Culturas de Chile. Prehistoria. Desde sus orígenes hasta los albores de la Conquista, J. Hidalgo, V. Schiappacasse, H. Niemeyer, C. Aldunate \& I. Solimano, Eds., pp. 81-105. Santiago: Editorial Andrés Bello.

— 2006. Asentamientos formativos complejos en el centro-sur andino: Cuando la periferia se constituye en núcleo. Boletín de Arqueología PUCP 10: 321-356, Lima.

NúÑEZ, L. \& C. SANTORO, 2011. El tránsito arcaico-formativo en la circumpuna y valles occidentales del centro sur andino: hacia los cambios "neolíticos". Chungara 43: 487-530.

NúÑEZ, P., 1983. Aldeas tarapaqueñas, notas y comentarios. Chungara 10: 29-37.

Oeschger, H.; U. Siegenthaler, U. Schotterer \& A. Gugelmann, 1975. A box diffusion model to study the carbon dioxide exchange in nature. Tellus 27: 168-92, Berns.

PARKER PeARSON, M., 1982. Mortuary practices society and ideology: An ethnoarchaeological study. En Symbolic and structural archaeology, I. Hodder, Ed., pp. 99-114. Cambridge: Cambridge University Press.

Pellegrino, C., 2011. Propuesta de intervención de sitios arqueológicos en la quebrada de Tarapacá: el caso de la aldea de Caserones. Revista Werkén 14 (1): 87-104, Santiago.

RAFFINO, R., 1977. Las aldeas del Formativo inferior en la Quebrada del Toro (Provincia de Salta. Argentina). Obra del Centenario del Museo de La Plata, II, Antropología: 253-300, La Plata.

- 1990. Poblaciones indígenas de la Argentina. Buenos Aires: Editorial TEA.

Rapoport, A., 1969. House Form and Culture. New Jersey: PrenticeHall, Englewood Cliffs.

Reimer, P. J.; M. G. L., Baillie, E. Bard, A. Bayliss, J. W. Beck, P. G. Blackwell, C. Bronk Ramsey, C. E. Buck, G. S. Burr, R. L. Edwards, M. Friedrich, P. M. Grootes, T. P. Guilderson, I. Hajdas, T. J. Heaton, A. G. Hogg, K. A. Hughen, K. F. Kaiser, B. Kromer, F. G. McCormac, S. W. Manning, R. W. Reimer, D. A. Richards, J. R. Southon, S. Talamo, C. S. M. Turney, J. van Der Plicht \& C. E. Weyhenmeyer, 2009). IntCal09 and Marine09 radiocarbon age calibration curves, 0-50,000 years cal BP. Radiocarbon 51 (4): 1111-1150, Arizona.

Rivera, M., 2005. Arqueología del desierto de Atacama: La etapa formativa en el área de Ramaditas/Guatacondo. Santiago: Editorial Universidad Bolivariana Colección Estudios Regionales y Locales. 
Rivera, M.; A. Shea, A. Carevic \& G. Graffam, 1995-1996. En torno a los orígenes de las sociedades complejas andinas: Excavaciones en Ramaditas, una aldea formativa del desierto de Atacama, Chile. Diálogo andino 14/15: 205-239, Arica.

Romero, A. \& L. Briones, 1999. Co-37: Estado y planificación inca en Collahuasi (Provincia de Iquique, I Región, Chile). Estudios Atacameños 18: 141-149.

Stuiver M. \& T. F. Braziunas, 1993. 14C Ages of Marine Samples to 10,000 BC Radiocarbon 35 (1) 137-189, Arizona.

TARTAGlia. 1980. A revised chronology for northern Chile. En Prebistoric trails of Atacama: Archaeology of Northern Chile, C. Meighan \& D. True, Eds., pp. 5-22, Monumenta Archaeologica 7. Los Angeles: University of California, The Institute of Archaeology.

Trigger, B., 1967. Settlement archaeology-its goals and promise. American Antiquity 32 (2):149-160, Washington D. C.

1968. The determinants of settlement patterns. En Settlements archaeology, K. C. Chang, Ed., pp. 53-78. Palo Alto, California: National Press Books.

True, D., 1980. Archaeological investigations in Northern Chile: Caserones. En Prehistoric trails of Atacama: Archaeology of Northern Chile, Monumenta Archaeologica 7, C. Meighan \& D. True, Eds., pp. 139-178. Los Angeles: The Institute of Archaeology, University of California.

UrBina, S., 2007. Estudio arquitectónico del Pucara de Topaín (Región de Antofagasta, norte de Chile). Boletín de la Sociedad Chilena de Arqueología 40: 29-46, Santiago.

-2010. Asentamiento y arquitectura: Historia prehispánica tardía de las quebradas altas del río Loa. En Actas del XVII Congreso Nacional de Arqueología Chilena, pp. 865-876. Valdivia: Sociedad
Chilena de Arqueología, Dirección Museológica, Universidad Austral de Chile.

Urbina, S. \& L. Adán, 2006. Construcciones de uso público y su distribución en las quebradas tarapaqueñas durante el período Intermedio Tardío (900-1450 DC). Boletín de la Sociedad Chilena de Arqueología 39: 19-34, Santiago.

Urbina, S.; L. Adán, C. Moragas, S. Olmos \& R. Ajata, 2011. Arquitectura de asentamientos de la costa de Tarapacá, norte de Chile. Estudios Atacameños 41: 21-348.

Urbina, S.; L. AdÁn \& E. VIDAL, 2012. Architecture in the Coastal Desert. Andean Past 10: 289-294, Ithaca, Nueva York.

Uribe, M.; L. AdÁN \& C. AGüERO, 2002. El dominio del Inka, identidad local y complejidad social en las tierras altas del desierto de Atacama, Norte Grande de Chile (1450-1541 DC). Boletín de Arqueología PUCP: 301-336, Lima.

UrIBE, M. \& VIDAL, E., 2012. Sobre la secuencia cerámica del Período Formativo de Tarapacá (900 AC-900 DC): estudios en Pircas, Caserones, Guatacondo y Ramaditas, norte de Chile. Chungara 44 (2): 209-245.

URTON, G., 1988. La arquitectura pública como texto social: la historia de un muro de adobe en Pacariqtambo, Perú (1915-1985). Revista Andina 6: 225-261, Lima.

VIDAL, E., 2012. Etnoarqueología de la fiesta andina: El caso de la región cultural de Tarapacá. Actas del XVIII Congreso Nacional de Arqueología Chilena, pp. 229-240, Valparaíso: Sociedad Chilena de Arqueología, Departamento de Antropología, Universidad de Chile.

Willey, G., 1968. Settlement Archaeology: An appraisal. En Settlement Patterns, K. Chang, Ed., pp. 208-226. Palo Alto: National Press Books. 